OPEN ACCESS

Edited by:

Mingyue $L i$

Wistar Institute, United States

Reviewed by:

Dacheng Fan,

Emory University, United States

Huili Chen,

University of Florida, United States

Peiqiang Feng

Harvard University, United States

*Correspondence:

Jian Wang

jianwang08@163.com

Specialty section:

This article was submitted to

Translational Medicine,

a section of the journal

Frontiers in Medicine

Received: 30 July 2021 Accepted: 11 October 2021 Published: 25 November 2021

Citation:

Li J, Xie Q, Ma R, Li Y, Yuan J, Ren M,

$L i H$, Wang J, Lu D, Xu Z and Wang J

(2021) Recent Progress on the

Synergistic Antitumor Effect of a

Borneol-Modified Nanocarrier Drug

Delivery System

Front. Med. 8:750170.

doi: 10.3389/fmed.2021.750170

\section{Recent Progress on the Synergistic Antitumor Effect of a Borneol-Modified Nanocarrier Drug Delivery System}

\author{
Jinxiu Li ${ }^{1,2}$, Qian Xie ${ }^{1,2}$, Rong Ma ${ }^{1,2}$, Yong $L_{i}^{1,2}$, Jianmei Yuan ${ }^{1,2}$, Mihong Ren ${ }^{1,2}$, \\ Hongyan $\mathrm{Li}^{1,2}$, Jiajun Wang ${ }^{1,2}$, Danni Lu ${ }^{1,2}$, Zhuo $\mathrm{Xu}^{1,2}$ and Jian Wang ${ }^{1,2 *}$ \\ ${ }^{1}$ State Key Laboratory of Southwestern Chinese Medicine Resources, Chengdu, China, ${ }^{2}$ College of Pharmacy, Chengdu \\ University of Traditional Chinese Medicine, Chengdu, China
}

Borneol, a traditional Chinese medicine, can enhance therapeutic efficacy by guiding the active ingredients to the target site. Reportedly, borneol improves the penetration capacity of the nasal, cornea, transdermal, intestinal, and blood-brain barriers. Although nanotechnology dramatically changed the face of oncology by targeting tumor sites, the efficiency of nanoparticles delivered to tumor sites is very low, with only $0.7 \%$ of the total particles delivered. Thus, based on the penetration ability and the inhibition drug efflux of borneol, it was expected to increase the targeting and detention efficacy of drugs into tumor sites in nanocarriers with borneol modification. Borneol modified nanocarriers used to improve drug-targeting has become a research focus in recent years, but few studies in this area, especially in the antitumor application. Hence, this review summarizes the recent development of nanocarriers with borneol modification. We focus on the updated works of improving therapeutic efficacy, reducing toxicity, inhibiting tumor metastasis, reversing multidrug resistance, and enhancing brain targeting to expand their application and provide a reference for further exploration of targeting drug delivery systems for solid tumor treatment.

Keywords: borneol, nanocarrier, drug delivery, targeting, drug resistance, tumor therapy

\section{INTRODUCTION}

Malignant tumors are one of the most devastating diseases, seriously affecting human life worldwide. Presently, the main treatment of cancer involves surgical resection, radiotherapy, chemotherapy, or immunotherapy, much of which is often insufficient and can cause serious, burdensome, and undesirable side effects $(1,2)$. Moreover, some chemotherapeutics, such as paclitaxel (PTX) or doxorubicin, have a low solubility in water, resulting in poor preferential absorption in the gastrointestinal tract (GIT), lack of distribution selectivity, first-pass metabolism, and overexpression of drug efflux transporter pumps [e.g., P-glycoprotein (P-gp)], which reduce their bioavailability and limit their therapeutic effects. Hence, the therapeutic effect of a single drug is limited. Moreover, it has been reported that cancer becomes more heterogeneous with its progression, which further leads to the formation of a group of cancer cells, which, together with changes in tumor cell proliferation, invasion, and migration decreases the sensitivity, tumor recurrence, and adverse reactions $(3,4)$. Multidrug resistance (MDR) is a phenomenon that occurs 


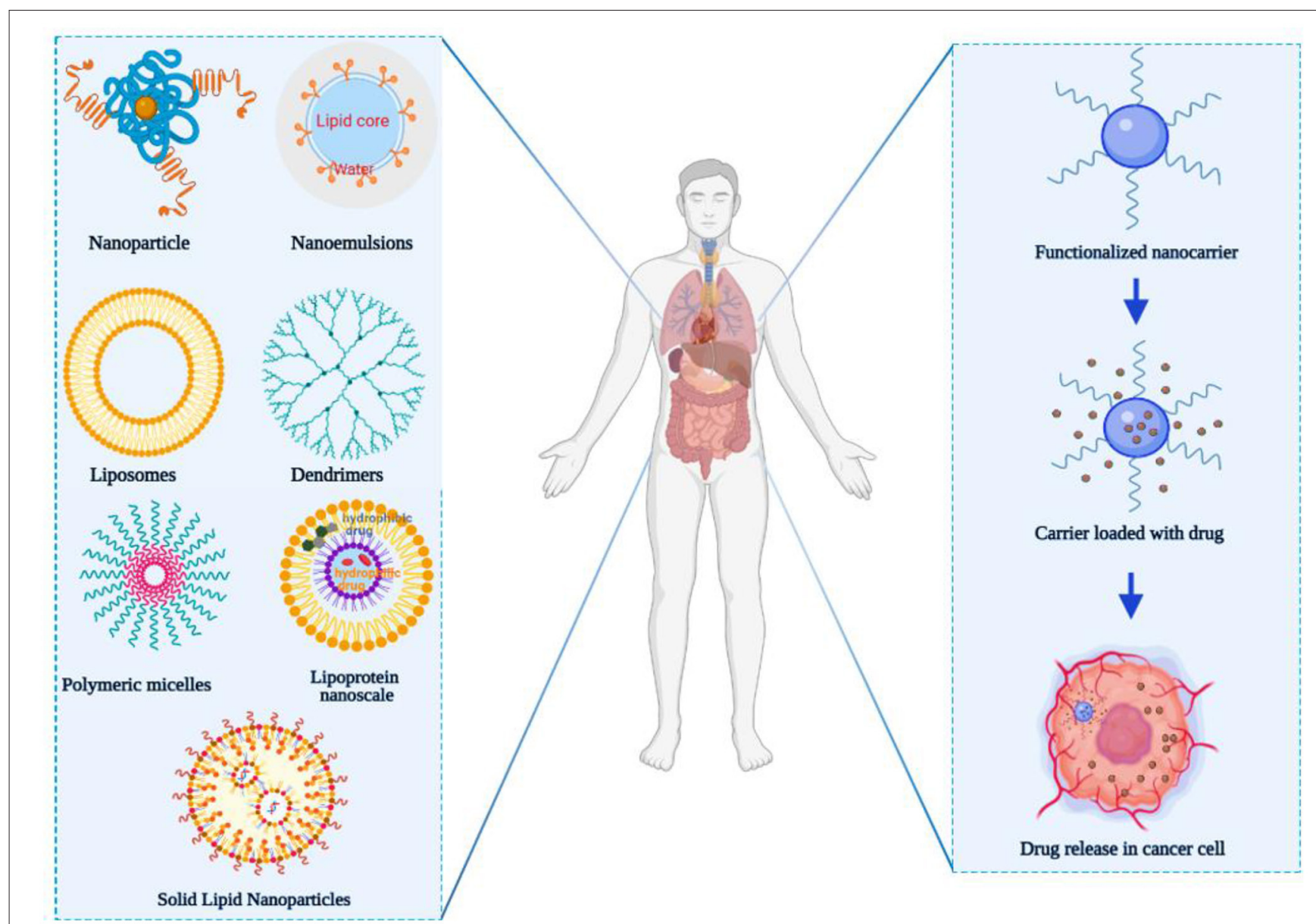

FIGURE 1 | Major classes of nanocarrier utilized for overcoming multidrug resistance (nanoparticle, nanoemulsions, liposomes, dendrimers, polymeric micelles, lipoprotein nanoscale, and solid lipid nanoparticles). The figure was created by BioRender, https://app.biorender.com/.

when cancer cells become resistant to multiple chemotherapeutic drugs with distinct structures and functions and remain a major hurdle to the successful treatment of various types of cancer (5). For a long time, the combination of anticancer drugs improved drug resistance and therapeutic effect (6). However, the different pharmacokinetics and lack of efficient drug delivery systems have greatly weakened their therapeutic effects.

Nanocarriers for drug delivery offer a novel idea for cancer treatment and have inspired many researchers. Nanocarriers can increase the concentration of a drug at the tumor site via the enhanced permeability and retention (EPR) effect, which also reduces systemic toxicity $(7-10)$. This phenomenon was first discovered by Matsumura and Maeda in 1986 when

Abbreviations: PTX, paclitaxel; GIT, gastrointestinal tract; P-gp, P-glycoprotein; MDR, multidrug resistance; EPR, enhanced permeability and retention; NPs, nanoparticles; TCM, traditional Chinese medicine; BBB, blood-brain barrier; AUC, area under the curve; MRP1, multidrug resistance-related protein-1; NB, natural borneol; ROS, reactive oxygen species; NSCLC, Non-Small Cell Lung Carcinoma; BUN, blood urea nitrogen; AST, aspartate aminotransferase; TP, total protein; GLB, Globulin; A/G, albumin/globulin ratio; HDL-C, high-density lipoprotein cholesterol; ABC, ATP-binding cassette; AKT, protein kinase B; MAPK, mitogenactivated protein kinase; MRT, mean residence time; CL, clearance. they observed that macromolecules $>50 \mathrm{kDa}$ preferentially distributed to the tumor tissues compared to normal tissues (11). In recent years, various nanocarriers, with different diameter, structures, and surface properties, including liposomes, polymer micelles, nanoparticles (NPs), dendrimers, nanoemulsions, and lipoprotein nanocomposites (Figure 1) have been designed for the specific delivery of anticancer drugs toward the tumor site (12-14). At present, some nanomedicines have been used in the clinic such as Doxil ${ }^{\circledR}$ (polyethylene glycol-modified liposome adriamycin) (15), micellized paclitaxel nanodrug Genexol ${ }^{\circledR}$-PM injection (16), and liposome vincristine Marqibo ${ }^{\circledR}$ (17). When nanocarriers interact with biological systems barriers, such as the skin epithelial barrier, the GIT, and the air-blood barrier, they serve as part of the primary defense system. These barriers prevent nanocarriers access into the deeper levels of organs affect the percentage of NPs that reach the diseased target tissue and cells (18). Biological barriers generally use common mechanisms to regulate the access of nanocarriers, whereas new mechanisms can be developed to block nanocarriers, especially in the tumor microenvironment, thereby further increasing the complexity of their behavior $(19,20)$. Additionally, NPs in the tumor matrix will also be affected by the cell-to-cell transport, 
enhanced permeability, retention effects, and may also compete with organs. Thus, the NPs delivered into tumor sites only account for $0.7 \%$ of the administered dose, which greatly hinders the clinical transformation of nanomedicine (21). Hence, how to solve the problem of NP delivery and its absorption and accumulation in tumor sites is extremely important. Borneol can promote the transdermal absorption of insoluble drugs and increase the blood concentration and bioavailability of drugs. Therefore, the introduction of borneol in nanocarriers is expected to increase the transmembrane absorption and the delivery volume to tumor tissues.

Borneol (Bing-Pian or Long-Nao) is a representative traditional Chinese medicine (TCM) resuscitation drug that has been used for more than 1,500 years. Borneol $\left(\mathrm{C}_{10} \mathrm{H}_{18} \mathrm{O}\right.$, molecular weight $154.25 \mathrm{Da}$ ) is a highly lipid-soluble bicyclic monoterpene with a fragrant odor and pungent and bitter taste. Borneol is a promising candidate for promoting the absorption of certain drugs and is generally used as a brain-refreshing drug in TCM. The borneol can be divided into the following three categories due to the differences in sources: natural borneol (NB, d-Borneol), levorotatory borneol (l-Borneol), and synthetic borneol (SB). Synthetic borneol comprises d-borneol and isoborneol, whereas natural borneol contains only d-borneol (22). Because some studies do not illustrate which type of borneol was utilized, we will simply use "borneol" in this manuscript. Borneol is widely regarded as a messenger drug that is considered capable of introducing main effective drugs in the prescription to the target site to increase therapeutic efficacy (23). This is consistent with the theory that "borneol is not potent enough when used alone; when it is used as an assistant or a messenger, borneol is effective" as described in the "Extension of the Materia Medica (Ben Cao Yan Yi)" (24). Moreover, borneol can promote the transdermal absorption of other drugs and increase their blood concentration and bioavailability (25). Therefore, it is a promising penetration enhancer based on its strong permeabilization effect. In addition, borneol can also prevent the efflux of drugs by inhibiting the function of P-gp and consequently increasing the accumulation of drugs and improving the therapeutic effect (26). Regarding the use of penetration enhancers, for instance, Azone was proved to promote transdermal penetration of both lipophilic and hydrophilic drugs. Furthermore, Azone, dimethyl sulfoxide (DMSO), decamethonium, glycocholate, and cholate are also used as ocular penetration enhancers in the laboratory. These penetration enhancers will easily generate irritability and toxicity, and the applicable concentrations are generally lower than those used on the skin owing to the corneal epithelium and the keratoderma being different in cellular type, pharmacokinetics, and metabolic processes and the cornea being sensitive to a chemical stimulus of foreign materials. For example, $0.1 \%$ Azone or a slightly higher concentration can cause ocular hypersensitivity, discomfort, or toxicity (27). Furrer et al. compared the ocular tolerance of nine potential absorption promoters, results indicated that DMSO, decamethonium, Tween 20, Brij 35, EDTA, glycocholate, and cholate caused about $16 \%$ of the corneal surface damaged, while sodium fusidate and saponin caused over $30 \%$ injured of the cornea
(28). Surfactants (for example, ethanol and propylene glycol) are added to formulations to solubilize lipophilic active ingredients, but anionic and cationic surfactants have the potential to damage human skin (29). In the "National Collection of Chinese Medicine Products" of China, there are 76 ophthalmic preparations, $73 \%$ of which contain borneol. Borneol could open the tight junctions and improve the permeability of the blood-optic nerve barrier reversibly by regulating the expression of claudin-5 and occluding (30). It has been noted that the opening of blood-brain barrier (BBB) by borneol was rapid, reversible, and causes transient physiological opening, which ensures the structural integrity of BBB (31). Borneol can be considered safe for oral consumption and U.S. Food and Drug Administration has listed borneol as a food ingredient. Natural and synthetic borneol at a concentration of $0.1 \%$ was safe for ocular administration and repeated administration for a long time without irritation, inflammation, sensitization, or corneal tissue damage $(32,33)$. These reports show that borneol not only has a great penetration enhancement effect, but is also with high safety and easy availability due to its low cost (34-36). Thus, the application of borneol in nanocarriers has great potential to improve the targeting and enhance the accumulation of chemotherapeutic drugs in tumors.

Here, this review first describes the recent research progress of borneol in combination with nanocarriers such as NPs, nanoemulsions, liposomes, dendrimers, polymer micelles, and lipoprotein nanocomposites for improving therapeutic efficacy, reducing the toxicity, inhibiting tumor metastasis, reversing MDR, and enhancing brain targeting in solid tumor treatment. Therefore, our review provides a theoretical reference for the further application of borneol in nanocarrier drug delivery systems.

\section{PENETRATION PROMOTING EFFECT AND MECHANISM OF BORNEOL}

Borneol is a cyclic terpene alcohol, and several studies have shown that it can enhance the diffusion of certain drugs across various physiologic barriers, such as the BBB (37), the cornea (38), the skin (39), and the mucous membrane (40, 41 ), indicating that borneol can be used as a transdermal penetration enhancer.

\section{Blood-Brain Barrier (BBB)}

It is reported that borneol can easily and rapidly cross the $\mathrm{BBB}$ due to its low molecular and high lipid solubility. The opening is a rapid, reversible, and transient physiological opening which causes no structural damage (31). Therefore, it is used as an adjuvant owing to its permeation-enhancing effects on various drugs across the $\mathrm{BBB}$ to treat central nervous system diseases. $\mathrm{BBB}$ is a special barrier between blood and brain tissue, which includes a structural barrier and a functional barrier. The structural barrier comprises tight junctions between vascular endothelial cells, endothelial cellcell junctions, basement membrane, and astrocytes (42). The functional barrier is mainly comprising ATP-binding cassette 
$(\mathrm{ABC})$ transporters including P-gp, multidrug resistance proteins $1 \mathrm{a}$ and $1 \mathrm{~b}$ (MDR $1 \mathrm{a}$ and MDR 1b), multidrug resistanceassociated protein 1 (MRP 1), MRP 4, and MRP 5, and the breast cancer resistance proteins (BCRP), among which P-gp is the most in-depth study. P-gp is a drug efflux pump, which can prevent the entry of drugs from blood into the brain $(22,43)$. The permeability-enhancing effects of borneol are closely associated with the inhibition of efflux protein function (44). In addition, borneol opens the tight junctions in BBB by modulating the expression of proteins of proteins like claudin and occluding (45). Borneol may also enhance pinocytosis in brain capillary endothelial cells, thereby promoting the transcellular passage of drug moieties. Taken together, alteration in cell membrane lipid structures, modulation of multiple ATPbinding cassette transporters, and tight junction proteins are the major contributing factors to BBB opening functions of borneol.

It has been shown that synthetic borneol maintained the cisplatin in the mouse brain at high concentrations for a long duration. The mechanism was that borneol increased the expression of ZO-1 and intercellular cell adhesion molecule1 (ICAM-1), and inhibited the expression of P-gp (44). The intraperitoneal injection of cisplatin after oral administration of L-borneol promoted the entry of cisplatin into brain tissue. The mechanism was that borneol promoted the opening of the $\mathrm{BBB}$ by the loss of tight junction proteins including occluding and claudin 5 at $1 \mathrm{~h}$ after the intravenous injection of L-borneol (45). Moreover, a borneol/menthol eutectic mixture promoted the transport of cobalt toxin into the brain by coadministration with borneol through the nasal-brain pathway by opening the tight junctions between the cells (46). Oral administration of borneol at different intervals has also been shown to increase the quantity and velocity of geniposide permeating in the brain, especially after $15 \mathrm{~min}$ of intragastric borneol at which point the $\mathrm{BBB}$ is most open (47). Borneol enhanced the antidepressant effects of asiaticoside by promoting its penetration of the $\mathrm{BBB}$, thus enhancing the anti-depressant effects with enhanced 5-HT and BDNF, and reduced TNF- $\alpha$ levels (48). Furthermore, the brain bioavailability of geniposide was found to be enhanced effectively. The possible mechanism may be that borneol could bind to the site on the cellular membrane or adsorb to the membrane surface to improve the membrane fluidity of the epithelium, increasing the orderly arrangement of cellular membrane phospholipid molecule chains, and reducing the collision with phospholipid molecules when a drug crosses the membrane. Thereby facilitating drug permeation. The levels of the tight junction (TJ) proteins localized in cell-cell junctions were decreased when cells were exposed to borneol, suggesting an impairment of the intercellular junctions, and increased paracellular permeability (49) (Table 1).

In recent time, some studies have been conducted to explore the potential of combining borneol with various nanocarriers to improve pharmacokinetics along with the dynamics of the drugs toward the brain. Borneol also increased the uptake of NPs when borneol and aprotinin-conjugated poly (ethylene glycol)poly (L-lactic-co-glycolic acid) NPs (Apr-NP) were cocultured with brain capillary endothelial cells (BCECs), suggesting that borneol enhanced NPs delivery into the brain by loosening the intracellular tight junction in $\mathrm{BBB}$ and accelerating the transportation of substance through the intercellular passage (57). Moreover, lactoferrin (Lf) co-modified NPs with borneol modification (Lf-BNPs) increased cellular uptake of $16 \mathrm{HBE}$ cells in vitro. Borneol and Lf co-modified NPs not only enhance the penetration and transport of dopamine through the nasal mucosa, but also enhance the drug delivery by opening the tight junctions of the BBB (58). There are two main methods for borneol to modify the carrier: the physical mixing method (physical modification) and the chemical synthesis method (chemical modification). At present, most of the modification are the physical modification, which mixed borneol and other lipophilic ingredients physically. The temperature needs to be controlled during the process owing to the sublimation of borneol. The chemical modification is borneol covalently combined with lipid materials based on a hydroxyl group structure of borneol through a certain chemical reaction. Song et al. compared the enhancing efficiency of solid lipid NPs between chemical (BO-SLN/CM) or physical modification with borneol (BO-SLN/PM). The results demonstrated that BOSLN/CM exhibited lower cytotoxicity, higher cell uptake, and better brain targeting when compared with BO-SLN/PM. In addition, BO-SLN/CM had a remarkable targeting ability to the brain, while BO-SLN/PM was concentrated at the lung (59). A study explored whether the borneol modified SLNs loaded with Pueraria flavone chemically (PTF-Bo-SA-SLNs) and physically (PTF-Bo-SLNs) improve brain delivery following intranasal administration. The results showed that both PTF-Bo-SA-SLNs and PTF-Bo-SLNs promoted the uptake of PTF by Caco-2 cells in a time and concentration-dependent manner, among them, the PTF-Bo-SA-SLNs showed better uptake especially at high concentrations, which may be associated with the directly conjugated borneol on the nanoparticle surface. In addition, PTF-Bo-SA-SLNs increased the AUC and $\mathrm{C}_{\max }$ of PTF in the plasma to 4.44- and 4.41-fold compared with PTF-BoSLNs, which suggested borneol modification could improve the absorption of PTF into plasma. There are two main direct pathways of entry into the brain after intranasal administration, namely, the olfactory and the trigeminal pathway. PTF-Bo-SASLNs and PTF-Bo-SLNs can be transported directly from the nasal cavity into the brain through the olfactory region of the nasal epithelium and the trigeminal neural region avoiding the BBB (60). Furthermore, borneol co-modified liposomes loaded with palmitate azidothymidine have been shown to enhance the transportation of drugs to the brain and increase the accumulation of azidothymidine by 3.73 -fold, indicating that the addition of $10 \%$ borneol enhances the transportation of drugs in the brain by loosening the tight junctions of BBB (61). Ganciclovir (GCV)-loaded solid lipid NPs with borneol (GCVb-SLN) enhanced the transport of GCV to the brain and extended the residence time is probably because of a combined function of SLNs and borneol. SLNs can inhibit the drug efflux, open the tight junctions of the brain capillary endothelial cells, and through the brain capillary endothelial cells endocytosis or transcytosis. Borneol markedly loosens the intercellular tight junctions in the $\mathrm{BBB}$ and accelerates the transport of substances through the intercellular passages, and 
TABLE 1 | The penetration promoting effect of borneol in brain, corneal, nasal mucosa, skin, and gastrointestinal mucosa.

\begin{tabular}{|c|c|c|c|c|c|c|}
\hline $\begin{array}{l}\text { Penetration } \\
\text { target site }\end{array}$ & Drug & Absorption enhancer & Administration & Index & Mechanism & References \\
\hline \multirow[t]{6}{*}{ Brain } & / & $10 \%$ borneol corn oil & Intragastrical & $\begin{array}{l}\text { Occludin, ZO-1, NOS, P-gp, } \\
\text { ICAM-1 }\end{array}$ & $\begin{array}{l}\text { Increased ICAM-1; } \\
\text { opening of the BBB }\end{array}$ & $(44)$ \\
\hline & Cisplatin & L-borneol & $\begin{array}{l}\text { Intragastrical } \\
\text { administration }\end{array}$ & $\begin{array}{l}\text { Evans blue leakage, cisplatin } \\
\text { concentrations in peritumoral } \\
\text { tissue and tumor loci, the median } \\
\text { survival period, Occluding, } \\
\text { Claudin-5 }\end{array}$ & $\begin{array}{l}\text { Loosen the } \\
\text { intercellular tight } \\
\text { junction in the BBB }\end{array}$ & $(45)$ \\
\hline & Cobrotoxin & $\begin{array}{l}\text { Borneol/menthol } \\
\text { eutectic mixture } \\
\text { (+BMEM) }\end{array}$ & Intranasal administration & $\begin{array}{l}\text { AUC; prolonged time values to } \\
\text { peak concentrations }\end{array}$ & $\begin{array}{l}\text { Loosen the tight } \\
\text { junctions between the } \\
\text { cells }\end{array}$ & (46) \\
\hline & Geniposide & Borneol & $\begin{array}{l}\text { Borneol: } \\
\text { intragastric administration } \\
\text { geniposide: iv }\end{array}$ & $\begin{array}{l}\mathrm{C}_{\max } \text { AUC; mean residence time } \\
\text { n(MRT); } T_{\max }\end{array}$ & BBB opening & $(47)$ \\
\hline & Asiaticoside & Borneol & $\begin{array}{l}\text { Intragastric } \\
\text { administration }\end{array}$ & $\begin{array}{l}\text { Increased rat brain AS levels, } \\
\text { BDNF, 5-HT; } \\
\text { Decreased TNF- } \alpha\end{array}$ & Opening the BBB & $(48)$ \\
\hline & Geniposide & Borneol and muscone & / & $\begin{array}{l}\text { Enhanced permeability- effect of } \\
\text { MDCK-MDR1 cells; increased } \\
\text { the fluxes of geniposide in both } \\
\text { directions in a } \\
\text { concentration-dependent } \\
\text { manner }\end{array}$ & TJ protein decreased & (49) \\
\hline \multirow[t]{7}{*}{ Corneal } & $\begin{array}{l}\text { Puerarin eye drops } \\
\text { and timolol } \\
\text { maleate eye drops }\end{array}$ & Borneol & / & $\begin{array}{l}\text { Q: the accumulated release } \\
\text { amount within time t, the } \\
\text { homeostasis flow rate } \mathrm{J} \text {, } \\
\text { permeability parameter Kp }\end{array}$ & / & (32) \\
\hline & $\begin{array}{l}\text { Indomethacin, } \\
\text { dexamethasone }\end{array}$ & $\begin{array}{l}\text { Synthetic borneol and } \\
\text { natural borneol }\end{array}$ & / & $\begin{array}{l}\text { The apparent permeability } \\
\text { coefficient (Papp), level of } \\
\text { corneal hydration, }\end{array}$ & $\begin{array}{l}\text { Loosen the tight } \\
\text { junctions between } \\
\text { epithelial cells }\end{array}$ & (33) \\
\hline & Danshensu & Borneol & $\begin{array}{l}\text { Intragastric } \\
\text { administration }\end{array}$ & $\begin{array}{l}\text { Danshensu concentrations in } \\
\text { plasma, aqueous humor, and } \\
\text { vitreous humor, peak times } \\
\text { (Tmax), }\end{array}$ & / & (30) \\
\hline & / & Synthetic borneol & Borneol gastric lavage & $\begin{array}{l}\text { Claudin- } 5 \text { and occluding in } \\
\text { endothelial cells distribution and } \\
\text { the mRNA, protein level }\end{array}$ & $\begin{array}{l}\text { Translocation of } \\
\text { claudin-5 and } \\
\text { occluding }\end{array}$ & (34) \\
\hline & Fluconazole & Menthol and borneol & / & $\begin{array}{l}\text { Fluconazole concentration } \\
\text { assay; the apparent corneal } \\
\text { permeability coefficient (Papp); } \\
\text { the transport enhancement ratios } \\
\text { (ER); corneal hydration levels }\end{array}$ & $\begin{array}{l}\text { Improved the } \\
\text { membrane fluidity; } \\
\text { reduced the collision } \\
\text { with phospholipid } \\
\text { molecules }\end{array}$ & (35) \\
\hline & $\begin{array}{l}\text { Rhodamine B, } \\
\text { sodium- } \\
\text { fluorescein, } \\
\text { fluorescein } \\
\text { isothiocyanate } \\
\text { (FITC) }\end{array}$ & Borneol & / & $\begin{array}{l}\text { Increased the apparent } \\
\text { permeability coefficient (Papp) } \\
\text { and Draize score, maintained the } \\
\text { corneal hydration values }<83 \% \text {; } \\
\text { enhanced the drugs into the eye }\end{array}$ & $\begin{array}{l}\text { Loosen the corneal } \\
\text { epithelium junctions } \\
\text { reversibly }\end{array}$ & (50) \\
\hline & Geniposide (Ge) & Natural borneol & $\begin{array}{l}\text { Ophthalmic } \\
\text { administered }\end{array}$ & $\begin{array}{l}\text { Concentrations of Ge; apparent } \\
\text { permeability coefficient (Papp); } \\
\text { AUC }_{0-6 h} ; \mathrm{C}_{\max }\end{array}$ & $\begin{array}{l}\text { NB enhanced } \\
\text { epithelial junction } \\
\text { permeability and } \\
\text { promoted paracellular } \\
\text { drug absorption. }\end{array}$ & (36) \\
\hline Skin & $\begin{array}{l}\text { 5-fluorouracil, } \\
\text { antipyrine, aspirin, } \\
\text { salicylic acid and } \\
\text { ibuprofen }\end{array}$ & Borneol & Transdermal permeation & $\begin{array}{l}\text { Irritant profile analyzed by } \\
\text { transepidermal water loss } \\
\text { (TEWL); molecular organization } \\
\text { of SC lipids detected by } \\
\text { ATR-FTIR }\end{array}$ & $\begin{array}{l}\text { Interact or associate } \\
\text { with the SC lipids alkyl } \\
\text { chains }\end{array}$ & (51) \\
\hline
\end{tabular}


TABLE 1 | Continued

\begin{tabular}{|c|c|c|c|c|c|c|}
\hline $\begin{array}{l}\text { Penetration } \\
\text { target site }\end{array}$ & Drug & Absorption enhancer & Administration & Index & Mechanism & References \\
\hline & Transdermal drugs & Borneol and menthol & Transdermal permeation & $\begin{array}{l}\text { Decreased the expression of } \\
\text { MDR1and P-gp; reduced Rh123 } \\
\text { efflux; increased Rh123 } \\
\text { accumulation }\end{array}$ & Inhibit MDR1and P-gp & $(52)$ \\
\hline & 5-fluorouracil & Borneol and menthol & In vitro permeation & $\begin{array}{l}\text { Disrupted SC morphology; } \\
\text { induced a slight curvature in the } \\
\text { SC bilayer; increased diffusion } \\
\text { coefficient of } 5 \text {-FU }\end{array}$ & $\begin{array}{l}\text { Menthol: disruption of } \\
\text { the stratum corneum } \\
\text { (SC) bilayer borneol: } \\
\text { the disruption of the } \\
\text { SC bilayer, increased } \\
\text { the diffusion, induced } \\
\text { the formation of } \\
\text { transient pores }\end{array}$ & (53) \\
\hline \multirow[t]{2}{*}{$\begin{array}{l}\text { Gastrointestinal } \\
\text { mucosa }\end{array}$} & $\begin{array}{l}\text { Notoginsenoside } \\
\text { R1 (NGR1), } \\
\text { Ginsenosides Rg1 } \\
\text { (GRg1) and Re } \\
\text { (GRe) }\end{array}$ & Borneol & $\begin{array}{l}\text { Intragastric } \\
\text { administration }\end{array}$ & $\begin{array}{l}\text { Increased bioavailability, the } \\
\text { quantities of NGR1, GRg1, and } \\
\text { GRe in rabbit tissues and Papp }\end{array}$ & $\begin{array}{l}\text { Loose intercellular } \\
\text { tight junction }\end{array}$ & (54) \\
\hline & Curcumin & Borneol & $\begin{array}{l}\text { Intragastric } \\
\text { administration }\end{array}$ & $\begin{array}{l}\text { Increased } \mathrm{AUC}_{0-\mathrm{t}}, \mathrm{C}_{\max } \text { and } \\
\text { Papp }\end{array}$ & No description & (55) \\
\hline Nasal mucosal & Geniposide (Ge) & Borneol and muscone & / & $\begin{array}{l}\text { Immunostaining of TJ proteins; } \\
\text { decreased transepithelial } \\
\text { electrical resistance (TEER); } \\
\text { increased apparent permeability } \\
\text { coefficient (Papp) and } \\
\text { fluorescence recovery rate (R); } \\
\text { efflux ratio (ER); }\end{array}$ & $\begin{array}{l}\text { Reduce drag of } \\
\text { phospholipids of the } \\
\text { lipid bilayer in the } \\
\text { nasal epithelium; loose } \\
\text { intercellular tight } \\
\text { junction; increase the } \\
\text { number and volume of } \\
\text { pinocytosis esicles in } \\
\text { BBB cells }\end{array}$ & (56) \\
\hline
\end{tabular}

significantly inhibited the activity of P-gp (62). Moreover, borneol and ginkgolide encapsulated liposomes (GGB-LP) enhanced the $\mathrm{BBB}$ permeability of ginkgolide and increased the uptake of bEND. 3 cells, resulting in improved targeting and distribution in the brain tissue by loosening intercellular tight junctions, opening the $\mathrm{BBB}$, and enhancing the distribution of drugs in the brain (63)

(Table 2).

\section{Corneal}

The cornea consists of six different layers, epithelium, Bowman's membrane, stroma, Dua's layer, Descemet's membrane, and endothelium, which build a barrier to the entry of the drug into the inner eye (68). Due to the existence of tight junctions, the corneal epithelial barrier limits the entry of drugs not only through the transcellular pathway, but also through the paracellular pathway, thus limiting their therapeutic effects (69). Borneol is widely used in ophthalmic preparations for treating ocular diseases. Borneol has also been shown to reduce the drag of phospholipids of the lipid bilayer in corneal epithelium to drug passage and loosen the tight junctions existing in the corneal epithelium, thereby allowing the paracellular transport of hydrophilic drugs and inducing drugs to pass through the cornea (70). Compared to other penetration enhancers, the major advantages of borneol are its wide use for ocular disease and long-term clinical safety.
The study demonstrated that $0.1 \%$ borneol increased corneal epithelial permeability to lipophilic and hydrophilic drugs in vitro, particularly hydrophilic drugs, and did not increase corneal hydration and damage the cornea and other ocular tissues. The mechanism by which borneol enhances hydrophilic drug permeation of the cornea by loosening the tight junctions between epithelial cells, which in turn, accelerate the passage of hydrophilic materials through the epithelium via the paracellular route (33). The corneal barrier consists of the epithelium, stroma, and endothelium, which form the three primary layers through which substances can permeate. The epithelium is the main barrier for water-soluble drugs, while the endothelium and stroma are the main barriers for many lipophilic drugs. Borneol, which is a lipophilic substance, may have some influence on the permeability of the stroma. Thus, borneol may have enhanced the cornea penetration of lipophilic puerarin, while it has little influence on the corneal penetration of hydrophilic timolol maleate (32). Li et al. demonstrated that borneol could enhance the diffusion of Danshensu across the ocular-blood barrier, but the detailed mechanism of its osmosis-promoting function needs to be investigated further (30). Additionally, borneol could loosen the blood-optic nerve barrier reversibly without causing damage by regulating the reversible translocation of two tight junction proteins (claudin5 and occluding) between the cell membrane and the cytoplasm to improve the permeability of the blood-optic nerve barrier, 
TABLE 2 | Nanomedicine co-modification and co-administration with borneol can enhance drug delivery and absorption to the brain, skin, and gastrointestinal mucosa.

\begin{tabular}{|c|c|c|c|c|c|c|c|c|}
\hline Disease & Drug & $\begin{array}{l}\text { Nanomedicines drug } \\
\text { delivery system }\end{array}$ & Animal model & Cell & Administration & Action results & Mechanism & References \\
\hline \multicolumn{9}{|l|}{ BBB } \\
\hline$A D$ & Huperzine A (Hup A) & $\begin{array}{l}\text { Aprotinin-conjugated } \\
\text { poly (ethyleneglycol)-poly } \\
\text { (Llactic-co-glycolic acid) } \\
\text { nanoparticles (Apr-NP) }\end{array}$ & $\begin{array}{l}\text { Balb/c nude mice; } \\
\text { Sprague-Dawley (SD) } \\
\text { rats }\end{array}$ & $\begin{array}{l}\text { Mouse brain } \\
\text { capillary } \\
\text { endothelial cells } \\
\text { (BCECs) }\end{array}$ & Injected by tail vein & $\begin{array}{l}\text { Borneol could enhanced the } \\
\text { cell uptake of nanoparticles } \\
\text { Greatly and the distribution } \\
\text { of the nanoparticles into the } \\
\text { brain, improved the brain } \\
\text { targeting efficiency of } \\
\text { nanoparticles and memory } \\
\text { impairment of AD rats. }\end{array}$ & $\begin{array}{l}\text { Loose the intracellular } \\
\text { tight junction }\end{array}$ & (57) \\
\hline $\begin{array}{l}\text { Parkinson's } \\
\text { disease (PD) }\end{array}$ & Dopamine & $\begin{array}{l}\text { Borneol and lactoferrin } \\
\text { co-modified } \\
\text { nanoparticles (Lf-BNPs) } \\
\text { encapsulated dopamine }\end{array}$ & Male SD rats & $\begin{array}{l}\text { SH-SY5Y, } 16 \text { HBE } \\
\text { cells }\end{array}$ & $\begin{array}{l}\text { Intranasal } \\
\text { administration }\end{array}$ & $\begin{array}{l}\text { Lf and borneol co-modified } \\
\text { NPs significantly increased } \\
\text { the cellular uptake and } \\
\text { promoted dopamine } \\
\text { delivery to the brain via the } \\
\text { intranasal route, restored } \\
\text { dopamine level in the } \\
\text { lesioned striatum of } \\
6 \text {-OHDA-induced PD rats }\end{array}$ & No description & (58) \\
\hline I & / & $\begin{array}{l}\text { Borneol-modified } \\
\text { chemically solid lipid } \\
\text { nanoparticle } \\
\text { (BO-SLN/CM) and } \\
\text { physically solid lipid } \\
\text { nanoparticle } \\
\text { (BO-SLN/PM) }\end{array}$ & Kunming mice & HBMECs cells & Injected via tail vein & $\begin{array}{l}\text { Borneol significantly } \\
\text { reduced the toxicity of SLN } \\
\text { to HBMECs at high } \\
\text { concentrations, improved } \\
\text { the ability of cell migration, } \\
\text { excellent enhancement of } \\
\text { the BBB permeation, } \\
\text { entered the brain rapidly }\end{array}$ & $\begin{array}{l}\text { Improved in the fluidity } \\
\text { of phospholipid } \\
\text { molecules in the } \\
\text { membrane, the tight } \\
\text { junction disappeared, } \\
\text { cells shrank, and the } \\
\text { gap between cells } \\
\text { increased }\end{array}$ & (59) \\
\hline $\begin{array}{l}\text { Cerebrovascular } \\
\text { disease }\end{array}$ & $\begin{array}{l}\text { Pueraria flavones } \\
\text { (PTF) }\end{array}$ & $\begin{array}{l}\text { PTF-loaded SLNs were } \\
\text { modified with Bo by } \\
\text { physical and chemical } \\
\text { methods to synthesize } \\
\text { PTF-Bo-SA-SLNs and } \\
\text { PTF-Bo-SLNs }\end{array}$ & Male SD rats & Caco-2 cells & $\begin{array}{l}\text { Intranasal } \\
\text { administration }\end{array}$ & $\begin{array}{l}\text { Modified with borneol } \\
\text { increased the uptake of } \\
\text { PTF-Bo-SA-SLNs and } \\
\text { PTF-Bo-SLNs by Caco-2 } \\
\text { cells, showed the better } \\
\text { targeting effect, increased } \\
\text { the (AUC), } C_{\text {max }} \text {, and Bo } \\
\text { modified by chemistry } \\
\text { method is better than by } \\
\text { physical method }\end{array}$ & No description & (60) \\
\hline $\begin{array}{l}\text { HIV } \\
\text { encephalopathy }\end{array}$ & $\begin{array}{l}\text { Azidothymidine } \\
\text { palmitate }\end{array}$ & $\begin{array}{l}\text { Azidothymidine palmitate } \\
\text { liposomes with 10\% } \\
\text { borneol (10\%B-AZTPL) }\end{array}$ & $\mathrm{KM}$ mice & I & Injected by tail vein & $\begin{array}{l}10 \% B-A Z T P L \text { significantly } \\
\text { increased AZTP } \\
\text { permeability into brain } \\
\text { tissues, shortened the time } \\
\text { to reach the peak and } \\
\text { increased the peak } \\
\text { concentration }\end{array}$ & $\begin{array}{l}\text { Borneol loosen the } \\
\text { tight junctions of BBB }\end{array}$ & (61) \\
\hline
\end{tabular}


TABLE 2 | Continued

\begin{tabular}{|c|c|c|c|c|c|c|c|c|}
\hline Disease & Drug & $\begin{array}{l}\text { Nanomedicines drug } \\
\text { delivery system }\end{array}$ & Animal model & Cell & Administration & Action results & Mechanism & References \\
\hline $\begin{array}{l}\text { Cytomegalovirus } \\
\text { (CMV) infection }\end{array}$ & Ganciclovir (GCV) & $\begin{array}{l}\text { GCV solid lipid } \\
\text { nanoparticles containing } \\
\text { borneol (GCVb-SLN) and } \\
\text { GCV-SLN }\end{array}$ & KM mice & / & Injected by tail vein & $\begin{array}{l}\text { Borneol-modified SLNs } \\
\text { could increase the } \\
\text { distribution of GCV to brain } \\
\text { and } A \cup C_{0-T} \text { and } C_{\max } \text { in } \\
\text { mice liver and spleen }\end{array}$ & $\begin{array}{l}\text { Loose intercellular tight } \\
\text { junctions of the BBB }\end{array}$ & (62) \\
\hline Ischemic stroke & Ginkgolides (GG) & $\begin{array}{l}\text { Borneol-modified } \\
\text { ginkgolides liposomes } \\
\text { (GGB-LPs) }\end{array}$ & Male KM mice & $\begin{array}{l}\text { Rat brain } \\
\text { endothelia cells, } \\
\text { bEnd.3 }\end{array}$ & i.v. via the tail vein & $\begin{array}{l}\text { Increased the uptake of } \\
\text { bEND.3 cell, Cmax, } \\
\text { AUC }{ }_{0 \rightarrow \infty}, \text { MRT }\end{array}$ & $\begin{array}{l}\text { Enhance blood-brain } \\
\text { barrier permeability }\end{array}$ & (63) \\
\hline \multicolumn{9}{|l|}{ SKIN } \\
\hline $\begin{array}{l}\text { The effect of } \\
\text { S-BO on } \\
\text { lymphatic } \\
\text { targeting }\end{array}$ & $\begin{array}{l}\text { 7-ethyl-10- } \\
\text { hydroxycamptothec }\end{array}$ & $\begin{array}{l}\text { 7-ethyl-10- } \\
\text { hydroxycamptothecin } \\
\text { liposomes (SN-38-Lips) }\end{array}$ & $\mathrm{KM}$ male mice & $\begin{array}{l}\text { RAW264.7 cells of } \\
\text { KM male mice }\end{array}$ & $\begin{array}{l}\text { Subcutaneously } \\
\text { injected }\end{array}$ & $\begin{array}{l}\uparrow \text { Residence time, uptake of } \\
\text { lymph nodes, intracellular } \\
\text { and the medulla zone of } \\
\text { PLNs fluorescent intensity, } \\
\text { Cmax, t1/2, MRTO-24h, } \\
\mathrm{CL}, \mathrm{AUCO}-24 \mathrm{~h} \\
\downarrow \text { Injection-site retention not } \\
\text { cause inflammatory reaction } \\
\text { of injection site }\end{array}$ & $\begin{array}{l}\text { Opening the barrier } \\
\text { gap, accelerate the } \\
\text { movement of biofilm }\end{array}$ & (64) \\
\hline Gout & Colchicines & $\begin{array}{l}\text { Borneol-physically- } \\
\text { modified colchicine } \\
\text { ethosome (COL-bpES); } \\
\text { borneol-chemically- } \\
\text { modified colchicine } \\
\text { ethosome (COL-bcES). }\end{array}$ & $\begin{array}{l}\text { Male Sprague-Dawley } \\
\text { rats }\end{array}$ & HaCaT cell & $\begin{array}{l}\text { Coated above the } \\
\text { ankle skin }\end{array}$ & $\begin{array}{l}\uparrow \text { Penetration; AUC }(0-\infty) \text {; } \\
\text { AUC (0-t); C max } \\
\downarrow \text { Cytotoxicity; joint } \\
\text { circumference; TNF- } \alpha \text { PGE2 }\end{array}$ & No description & (65) \\
\hline Ischemic stroke & $\begin{array}{l}\text { Tetram-ethylpyrazine } \\
\text { (TMP) and borneol } \\
\text { (BN) }\end{array}$ & $\begin{array}{l}\text { TMP and BN } \\
\text { microemulsion } \\
\text { (TEM-BN-ME) }\end{array}$ & $\begin{array}{l}\text { Male Sprague-Dawley } \\
\text { rats; New Zealand } \\
\text { rabbits }\end{array}$ & / & / & $\begin{array}{l}\uparrow \text { AUC 0-inf; C max; } \\
\text { percutaneous absorption } \\
\text { and brain distribution of } \\
\text { TMP }\end{array}$ & $\begin{array}{l}\text { ATP-binding cassette } \\
\text { transporters, tight } \\
\text { junction protein, } \\
\text { enhancement of } \\
\text { vasodilatory } \\
\text { neurotransmitters }\end{array}$ & (66) \\
\hline \multicolumn{9}{|c|}{ GASTROINTESTINAL MUCOSA } \\
\hline $\begin{array}{l}\text { Pancreatic } \\
\text { carcinoma }\end{array}$ & $\begin{array}{l}\text { 9- } \\
\text { nitrocamptothecin(9- } \\
\text { NC) }\end{array}$ & $\begin{array}{l}\text { 9-NC-loaded PLGA } \\
\text { nanoparticles } \\
\text { (PLGA-NPs) }\end{array}$ & Male SD rats & / & $\begin{array}{l}\text { Intragastric } \\
\text { administration }\end{array}$ & $\begin{array}{l}\text { Borneol prolonged the } T_{\max } \text {, } \\
\text { increased the } C_{\max } \text {, } \\
\text { improved bioavailability and } \\
\text { enhanced intestinal } \\
\text { absorption. }\end{array}$ & Loose tight junction & (67) \\
\hline
\end{tabular}


while not changing the levels of claudin-5 or occluding (34). Menthol, combined with borneol, enhanced the ex vivo corneal permeability of fluconazole better than menthol alone. The possible mechanism may be that menthol has an alcoholic hydroxyl group, which is a hydrogen bond acceptor/donor. Furthermore, borneol could bind to the site on the cellular membrane or adsorb to the membrane surface to improve the membrane fluidity of the corneal epithelium, increase the orderly arrangement of cellular membrane phospholipid molecule chains, and reduce the collision with phospholipid molecules when fluconazole crosses the membrane, thereby facilitating drug permeation (35). Researchers found that borneol could increase rhodamine B, sodium-fluorescein, and FITCdextrans of $4 \mathrm{kDa}$ into the eye through the transcorneal pathways without causing ocular irritation and toxicity but failed to significantly corneal permeation of FITC-dextrans of 10, 20, and $40 \mathrm{kDa}$. The mechanism was that borneol quite possibly loosens the epithelium junctions in the cornea to an extent that is within a limit (50). Natural borneol enhanced the permeability and bioavailability of geniposide in the cornea, possibly because natural borneol is a small lipophilic compound and can be rapidly absorbed via the corneal tissue because of its liposolubility and low molecular weight. When passing through the corneal tissue, natural borneol might enhance epithelial junction permeability and promote paracellular drug absorption. In addition, no ocular damage or clinical abnormal signs were observed in the cornea, conjunctiva, or iris in ocular irritation tests (36) (Table 1).

Due to the existence of ocular blood-aqueous and bloodretinal physiological barriers, drug bioavailability $(<5 \%)$ after ocular administration is often very low. The major approaches that have been explored to improve ocular drug bioavailability are drug delivery systems and penetration enhancers or prodrug approaches (71). Nanoparticles (NPs) have been shown to enhance precorneal retention and provide sustained drug delivery. But there seem to be no applications of borneol coadministration with drugs co-loaded with nanocarriers in the cornea. One study chooses five penetration enhancers having different modes of action, namely, benzalkonium chloride (BAC), capric acid (CA), Ethylenediaminetetraacetic acid (EDTA), sodium glycocholate (SG), and sodium taurocholate (ST) to explore their effect on nanoparticle system [polycaprolactonepluronicF68 (PCL-PF68)] bioavailability to various ocular tissues. Results demonstrated that all the penetration enhancers enhanced the ocular permeability of PCL-PF68 nanoparticles to the anterior part of the eye except EDTA. BAC and CA increased bioavailability of PCL-PF68 nanoparticles in the conjunctiva, SG in the cornea, iris and ciliary body, and ST in the cornea. The mechanism was that SG and ST enhance drug delivery in the cornea by widening the tight junctions between cells, allowing penetration of drugs via the paracellular route, and affecting membrane fluidity (72). The above research shows that borneol can improve the membrane fluidity of the corneal epithelium, loosen the tight junctions between cells, and accelerate the passage of hydrophilic materials through the epithelium via the paracellular route $(33,50)$. Thus, the combination of borneol and surface properties of nanoparticles can differentially influence ocular permeability and bioavailability and can advantageously develop improved ocular drug delivery systems.

\section{Skin}

The biggest challenge of the transdermal drug delivery system is that it is difficult for the drug to penetrate the highly organized structure of the stratum corneum, which is the most impermeable barrier to the skin $(51,73)$. On the other hand, the diffusion of drug molecules in the stratum corneum will be affected by its intercellular lipids, which present a high resistance to the penetration of molecules into the inner layer of the epidermis (74). Penetration enhancers change the structure or consistency of the stratum corneum and adjust the solubility and thermodynamic activity of the drug to promote its diffusion across the skin (75). Although the incorporation of suitable chemical permeation enhancers is a well-established strategy, it is easy to cause skin allergy and irritation. Borneol is a highly lipophilic, low molecular weight, volatile monoterpene, and is widely used as penetration enhancers in clinics with high safety, low toxicity, and side effects $(51,76)$. It was proposed that skin penetration enhancers may act by one or more of three potential mechanisms. Firstly, borneol can alter the intercellular lipid structure between the corneocytes to increase diffusivity (77). Secondly, borneol can dilate the subcutaneous capillaries so that the drug can easily enter the blood circulation and promote absorption. Thirdly, they may regulate the expression of P-gp, thereby affecting the transport function and ultimately promoting drug absorption $(52,78)$.

Borneol could markedly enhance the transdermal absorption of five model drugs, namely 5-fluorouracil, antipyrine, aspirin, salicylic acid, and ibuprofen. The IC50 values of borneol were markedly higher in both HaCaT keratinocytes and CCC-HSF1 fibroblasts in comparison to those of the known standard enhancer Azone, a well-established and standard enhancer, indicating that borneol had relatively low toxicity on the skin cells. The molecular mechanism was that borneol could disrupt and extract part of the stratum corneum intercellular lipids, which would greatly perturb the orderly arrangement structure of the stratum corneum. In addition, borneol contributed negligibly to the alteration of the keratin conformation (51). Borneol has also been shown to reduce the collision and resistance between phospholipid molecules and increases its fluidity by changing the integrity of lipid cell membranes. On the other hand, there was a significant effect on the P-gp in the cell membrane, while no changes in the nucleus, thereby weakening drugs efflux and promoting the transdermal absorption (52). The comparative assessment indicated that borneol imparts a relatively stronger penetration-enhancement effect on 5fluorouracil when compared to menthol. The mechanism was that borneol imparts a stronger disruptive effect on the morphology of the stratum corneum owing to the interaction between borneol and the head group of stratum corneum lipids is stronger than that of menthol. Furthermore, borneol-induced the duration of transient pore existence time longer than menthol, thereby increasing the diffusion coefficient of 5-fluorouracil (53) (Table 1). 
Studies have been conducted to explore the potential of combining borneol with nanocarriers in transdermal drug delivery. Ye et al. (64) found that synthetic borneol (SBO) enhanced the lymphatic-targeting ability of 7-ethyl-10hydroxycamptothecin liposomes (SN-38-Lips) and reduced injection-site retention, prolonged residence time, and increased uptake of lymph nodes, which would not cause inflammatory reaction of the injection site. S-BO improved lymphatic uptake of SN-38-Lips via increasing cellular uptake of lymphocytes and macrophages in the lymph node, especially through phagocytosis of macrophages. SN-38-Lips did not show apparent change when were incubated with S-BO suspension for $12 \mathrm{~h}$, which may relate to that S-BO decrease the entrapment efficiency via accelerating the movement of biofilm. The mechanism was associated with the ability of borneol to open the barrier gap. Zhang et al. used colchicine (COL) as a model drug, prepared borneol physically modified colchicine ethosome (COL-bpES), and borneol chemically modified colchicine ethosome (COL-bcES) by connecting borneol (BO) and dioleoyl phosphoethanolamine (DOPE) with succinic anhydride. The particle diameter of the COL-bcES was lower than that of the COL-bpES, and the toxicity, in vitro diffusion, pharmacokinetics, and pharmacodynamics were all superior to those of COL-bpES. It was related to the extreme lipophilicity of borneol that it encapsulated into the lipid core of COL-bcES easily. Borneol of COL-bcES had a more stable distribution in the surface of nanocarrier when ethosome passed through the skin, which makes borneol take better effect (65). Hu et al. found that borneol enhances the percutaneous absorption and distribution of tetramethylpyrazine (TMP) in the brain without adverse effects on the skin when TMP and borneol are combined and incorporated into a microemulsionbased transdermal therapeutic system. The mechanism may be consistent with the previous study, which included the modulation of multiple ATP-binding cassette transporters, tight junction protein, and the predominant enhancement of vasodilatory neurotransmitters mediated by borneol (66) (Table 2).

\section{Gastrointestinal and Nasal Mucosal}

The inner wall of the gastrointestinal tract (GIT) is an important protective barrier as the presence of tight junctions prevents the entry of drugs through the paracellular pathway. At the same time, the $\mathrm{ABC}$ transporter that exists in the epithelial cells of the GI tract is involved in the efflux of various drugs back into the GI lumen, which also severely limits the permeability of drugs. Most nasal absorption enhancers, such as surfactants, overcome the transcellular barrier by disrupting the lipid structure of the cell membrane (56). EDTA facilitates paracellular transport by opening tight junctions $(54,79)$ and piperine promotes permeation of drugs by inhibiting the efflux pump $(55,80)$. The possible mechanisms of most nasal absorption enhancers include increasing membrane fluidity, reducing mucus viscosity or elasticity, inhibiting enzyme activity, inhibiting the efflux proteins, opening tight junctions, or dissolving drugs to enhance their diffusion (81). Borneol served as an effective penetration enhancer, which can play its penetration promotion role through most mechanisms described above.
Borneol promotes intestinal absorption, increases the tissue distribution, and inhibits the rapid metabolism of the notoginsenoside R1 and ginsenoside Rg1 and Re, possibly by loosening the intercellular tight junctions (54). Coincubation with borneol improved the apparent permeability coefficients (Papp) of curcumin (CUR) across the duodenum, jejunum, and ileum. The explicit reason was not described, just assumed that may be related to downregulation of ZO-1 and Factin associated with the tight junction, inhibition of the function and expression of $\mathrm{P}$-gp, and multidrug resistance-associated proteins, which were important transporters found in the small intestine, alteration of the lipid phase of the intestinal mucous membrane, and acceleration of the fluidity of the polar head group regions in cell membranes according to the previous studies (55). It has been found that the nasal transport of geniposide increased significantly when co-administrated with borneol and muscone. The drag of phospholipids of the lipid bilayer in the nasal epithelium is the major barrier for topically applied drugs. The enhancing effect of borneol and muscone on geniposide transport might be linked to the combined effect of opening the tight junction proteins and increasing membrane fluidity. The possible mechanism may be that borneol has an alcoholic hydroxyl group, which is a hydrogen bond acceptor/donor (56) (Table 1).

Borneol plays the same role in increasing the intestinal epithelium permeability of NPs and chemical compounds. The results of the preclinical pharmacokinetic study showed that $\mathrm{T}_{\max }(\mathrm{h})$ and $\mathrm{C}_{\max }(\mathrm{ng} / \mathrm{ml})$ values were significantly higher in nanoparticles (NPs) containing borneol $(2.00 \pm .81 \mathrm{~h}$ and $185.56 \pm 27.78 \mathrm{ng} / \mathrm{ml})$ as compared to 9-nitrocamptothecin (9-NC) solution $(0.25 \pm .77 \mathrm{~h}$ and $80.75 \pm 22.85 \mathrm{ng} / \mathrm{ml})$ and for NPs without borneol, it was $1.17 \pm .41 \mathrm{~h}$ and $111.06 \pm$ $18.87 \mathrm{ng} / \mathrm{ml}$, respectively. The relative bioavailability of NPs containing borneol was 383.90 and $150 \%$ with respect to $9-\mathrm{NC}$ solution and NPs without borneol, respectively. Poly lactic-coglycolic acid NPs (PLGA-NPs) of 9-NC containing borneol only promoted intestinal transport for NPs with diameter $<100 \mathrm{~nm}$ but not larger NPs. This may be explained by the ability of borneol to open tight junctions among intestinal epithelial cells and enhance the transport of smaller NPs through the paracellular pathway (67) (Table 2).

\section{Summary}

These studies indicate that borneol exerts a regulatory effect on the $\mathrm{BBB}$, cornea, skin, and mucous membrane permeability, which is considered as a strong penetration enhancer. The mechanism was generally interpreted as follows: Borneol could change the close connection between the epithelial cells (46, $50,56)$ and accelerate the transportation of drugs through the intercellular passage (54). It could also increase the number and volume of pinocytosis vesicles in BBB cells (56), improve cell membrane permeability (36), change the integrity of the lipid cell membrane, and decrease the collision and the resistance between phospholipid molecules to increase their fluidity. Finally, borneol could significantly inhibit the activity of drug resistance proteins such as multidrug resistance mutation 1 (MDR1) and P-gp and accelerate the transportation of drugs 


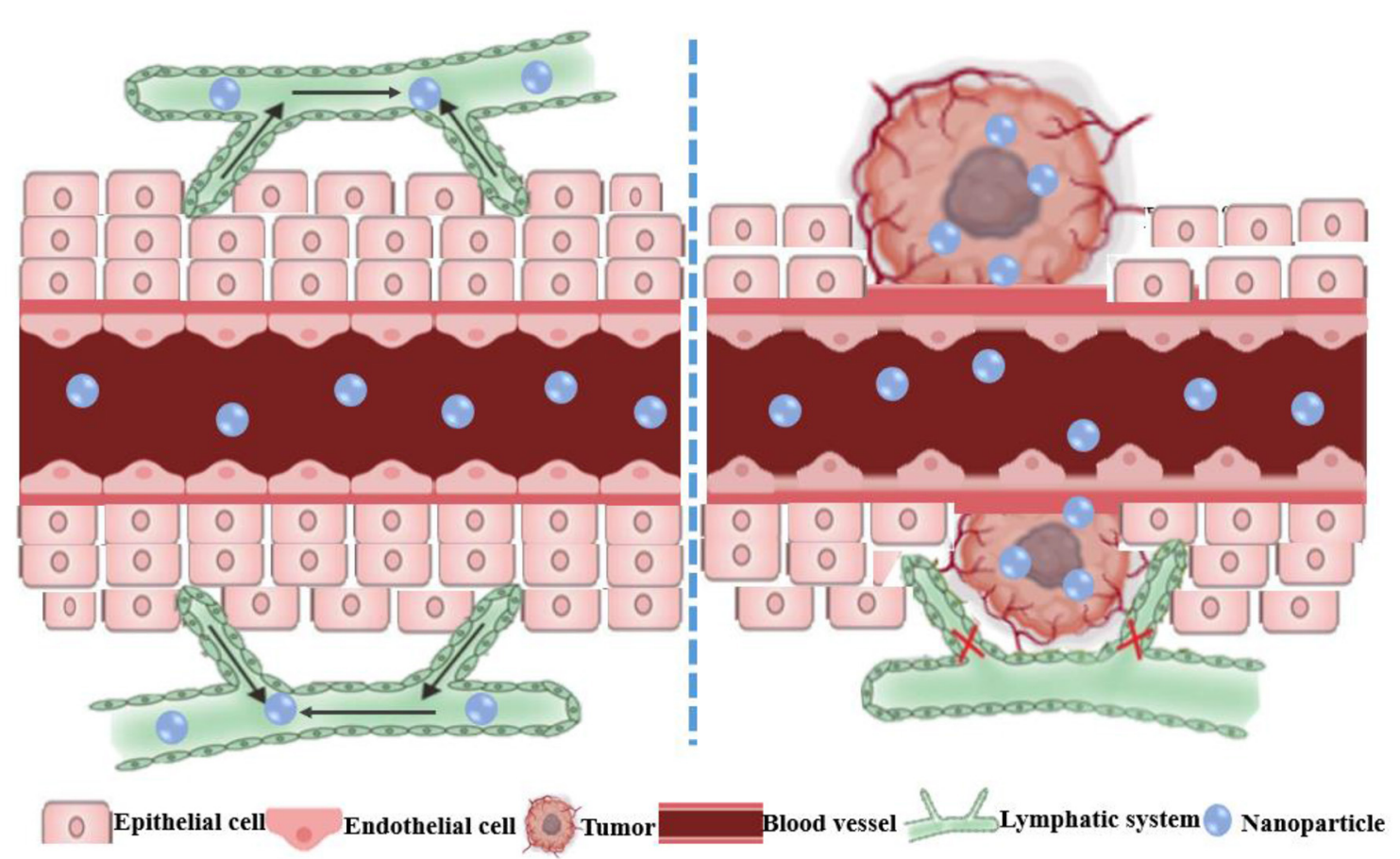

FIGURE 2 | Schematic diagram of the enhanced permeability and retention (EPR) effect of nanoparticles in tumors. The normal tissue has tight vascular endothelial to prevent the extravasation of macromolecules. The EPR effect is the result of the leaky vasculature and ineffective lymphatic drainage of the newborn tumor blood vessels, which results in the retention of macromolecules in the tumor.

(52). In addition, nanocarriers modified by borneol chemically show higher safety and better drug absorption properties than those modified physically. Therefore, it is necessary to review the effect of borneol co-modification with nanocarriers on the efficacy of antitumor.

\section{RECENT APPLICATION OF NANOCARRIERS CO-MODIFIED WITH BORNEOL FOR SOLID MALIGNANCIES}

Nanoparticles integrate small drug molecules into nanomaterials through encapsulation or adsorption to achieve effective drug delivery $(36,82)$. NPs specifically accumulate in tumors due to passive targeting via the EPR effect and the increased pore diameter and hydraulic conductivity of the vasculature (Figure 2) (83). Importantly, the conjugation of different antitumor drugs to NPs can not only reduce the toxic side effects caused by large doses of single drugs, but also enhance its overall performance effect of cancer cells through multiple pathways, thereby reversing MDR (84-86). An NP diameter between 20 and $200 \mathrm{~nm}$ can increase drug uptake and passive targeting through the EPR effect $(87,88)$. Nanocarriers extend the circulation time of the drug in the body by adding some modifications, which can reduce phagocytosis by mononuclear macrophages and the reticuloendothelial (89). For example, some nanocarriers modifications such as folic acid (90), hyaluronic acid (91), cell membrane penetrating peptide (92), transferrin (93), and biotin
(94) enhanced the targeting effect of chemotherapeutic drugs and increased the accumulation in the tumor site by binding to receptors that are specifically and highly expressed on the surface of tumor cells. In addition, many materials used for the modification of nanocarriers can reverse MDR, such as Poloxamer P85 (95), Poloxamer 188 (96), and polyethylene glycol vitamin E succinate (TPGS) (97).

Despite their promise, the efficiency of NPs delivered to tumor sites is low, with $<0.7 \%$ of the total amount reaching the target site (21), which greatly hinders the clinical transformation. Based on the strong penetration property of borneol, the introduction of borneol into the nanocarriers is expected to increase the transmembrane absorption and the delivery efficiency into tumor sites. However, there are few studies in this area, especially those with antitumor applications. In this study, we review the recent studies on nanocarriers that have been co-modified with borneol, including NPs, nanoemulsions, liposomes, dendrimers, polymer micelles, and lipoprotein nanocomposites for improving therapeutic efficacy, reducing the toxicity, inhibiting tumor metastasis, reversing $\mathrm{MDR}$, and enhancing brain targeting, to expand its application in targeted drug delivery systems in the treatment of solid tumors (Table 3).

\section{Improved Therapeutic Efficacy}

A previous study reported that borneol increased the transdermal absorption of drugs toward different barriers, which effectively increase the blood concentration and bioavailability of other 
TABLE 3 | Borneol modified nanoparticle-based drug delivery platforms.

\begin{tabular}{|c|c|c|c|c|c|c|c|}
\hline Tumor type & Drug & Structure & In vitro & In vivo & Action results & Mechanism & References \\
\hline \multicolumn{8}{|c|}{ NANOPARTICLES } \\
\hline Glioma & Paclitaxel & $\begin{array}{l}\text { Borneol combined with } \\
\text { CGKRK peptide modified } \\
\text { paclitaxel prodrug } \\
\text { self-assembled redox } \\
\text { responsive nanoparticles } \\
\text { (CGKRK-PSNPs) }\end{array}$ & $\begin{array}{l}\text { U87MG cells, } \\
\text { BCEC cells }\end{array}$ & $\begin{array}{l}\text { U87MG glioma-bearing } \\
\text { Balb/c nude mice, } \\
\text { CGKRK-PSNPs injected } \\
\text { via tail vein }\end{array}$ & $\begin{array}{l}\uparrow \text { Cellular uptake of nanoparticles, } \\
\text { cytoplasm uptake of PTX, proliferation } \\
\text { inhibition, migration efficiency of both } \\
\text { PEG-PSNPs and CGKRK-PSNPs } \\
\text { penetrating the in vitro BBB, glioma site } \\
\text { distribution of CGKRK-PSNPs combined } \\
\text { with Bor, medium survival time of mice } \\
\text { treated with CGKRK-PSNPs combined } \\
\text { with Bor }\end{array}$ & $\begin{array}{l}\text { Enhance BBB } \\
\text { penetration }\end{array}$ & (98) \\
\hline $\begin{array}{l}\text { Hepatocellular } \\
\text { carcinoma }\end{array}$ & $\begin{array}{l}\text { Selenium } \\
\text { nanoparticles } \\
\text { (SeNPs) }\end{array}$ & $\begin{array}{l}\text { Surface decoration of } \\
\text { galactosamine (GAL) and } \\
\text { Borneol (Bor)-modified } \\
\text { SeNPs (GAL/Bor @ } \\
\text { SeNPs) }\end{array}$ & $\begin{array}{l}\text { R-HepG2 cells } \\
\text { overexpressed } \\
\text { P-gp; L02 normal } \\
\text { hepatocyte }\end{array}$ & $\begin{array}{l}\text { Sprague-Dawley (SD) } \\
\text { mice }\end{array}$ & $\begin{array}{l}\uparrow \text { Drug accumulation and retention, } \\
\text { Cleaved-PARP, p-p53, p-ATM, p-BRCA1, } \\
\text { P-Histone (Ser139), p-JNK, p-p38, MAPK } \\
\downarrow \text { ABC family proteins, ROS, } \\
\text { caspase-3/8/9, p-AKT, p-ERK }\end{array}$ & $\begin{array}{l}\text { ABC family, p53 } \\
\text { pathway, MAPKs and } \\
\text { AKT pathway }\end{array}$ & (99) \\
\hline Glioma & Ginsenoside-Rh2 & $\begin{array}{l}\text { Ginsenoside-Rh2 lipid } \\
\text { nanoparticles }\end{array}$ & Glioma C6 cells & I & $\downarrow$ Cell proliferation & / & (100) \\
\hline NSCLC & Gefitinib & NBNPs & A549 cells & $\begin{array}{l}\text { A549-bearing Balb/c } \\
\text { nude mice }\end{array}$ & $\begin{array}{l}\uparrow \text { ROS generation, DNA damage, cell } \\
\text { apoptosis } \\
\downarrow \text { Cell proliferation, tumor weight, tumor } \\
\text { volume, the injury of heart, liver and kidney }\end{array}$ & $\begin{array}{l}\text { ROS, DNA damage, } \\
\text { apoptosis }\end{array}$ & (101) \\
\hline $\begin{array}{l}\text { Lung, breast, } \\
\text { cervical, } \\
\text { malignant } \\
\text { melanoma, liver, } \\
\text { and colon } \\
\text { cancer }\end{array}$ & $\begin{array}{l}\text { doxorubicin } \\
\text { (DOX) }\end{array}$ & PLGA@NB & $\begin{array}{l}\text { A549, HepG2, } \\
\text { SW480, MCF-7, } \\
\text { A375 cells }\end{array}$ & $\begin{array}{l}\text { A549-bearing Balb/c } \\
\text { nude mice }\end{array}$ & $\begin{array}{l}\uparrow \text { Drug accumulation, ROS generation, } \\
\text { cell apoptosis } \\
\downarrow \text { IC50, tumor weight, tumor volume, the } \\
\text { rate of tumor inhibition no heart, liver, and } \\
\text { kidney injury }\end{array}$ & ROS, apoptosis & (102) \\
\hline \multicolumn{8}{|c|}{ NANOEMULSION } \\
\hline Glioma & $\begin{array}{l}\text { Brucea javanica } \\
\text { oil }\end{array}$ & $\begin{array}{l}\text { Born4eol and Brucea } \\
\text { javanica oil nanoemulsion }\end{array}$ & Rat glioma C6 cells & $\begin{array}{l}\text { C6- bearing male Wistar } \\
\text { rats }\end{array}$ & $\begin{array}{l}\uparrow \text { The rate of tumor inhibition } \\
\downarrow \text { Tumor weight, tumor volume }\end{array}$ & $\begin{array}{l}\text { Open the BBB, } \\
\text { improved the brain } \\
\text { targeting and drug } \\
\text { distribution in the brain }\end{array}$ & $(103,104)$ \\
\hline NSCLC & Gefitinib & $\begin{array}{l}\text { Nanolization of NB } \\
\text { (NBNPs) }\end{array}$ & $\begin{array}{l}\text { A549, WI38 (normal } \\
\text { lung fibroblast cells) }\end{array}$ & $\begin{array}{l}\text { A549 tumor-bearing } \\
\text { female Balb/c nude } \\
\text { mice }\end{array}$ & $\begin{array}{l}\uparrow \text { RIPK1, FADD mRNA and protein level; } \\
\text { pharmacokinetic parameters ( } \mathrm{t}_{1 / 2 \beta}, \\
\left.\mathrm{AUC}_{0-24 h}, \mathrm{MRT}\right) \text {; survival rate; NB } \\
\text { concentration in the tumor region } \\
\downarrow \text { EHD1 mRNA and protein level; } \mathrm{Cl} \text {; } \\
\text { tumor volume index, tumor volume, tumor } \\
\text { weight; PCNA, Ki67 }\end{array}$ & $\begin{array}{l}\text { ROS generation, cell } \\
\text { apoptosis, } \\
\text { EHD1/FADD pathway }\end{array}$ & (105) \\
\hline \multicolumn{8}{|l|}{ LIPOSOMES } \\
\hline $\begin{array}{l}\text { Refractory or } \\
\text { recurrent brain } \\
\text { tumors }\end{array}$ & $\begin{array}{l}\text { Doxorubicin } \\
\text { hydrochloride, } \\
\text { I-borneol }\end{array}$ & $\begin{array}{l}\text { Doxorubicin } \\
\text { hydrochloride }\end{array}$ & I & $\begin{array}{l}\text { Dox-NanoLips were } \\
\text { injected by vein and } \\
\text { borneol }\end{array}$ & $\begin{array}{l}\uparrow M R T \text {, distribution phase rate constant } \\
(\alpha), A \cup C_{0-6 h} \text {, brain bioavailability and }\end{array}$ & Loose tight junction & (106) \\
\hline
\end{tabular}

A549 cells

\section{9-bearing Balb/c nude mice}

SW480, MCF-7,

A549-bearing Balb/c

nude mice $\downarrow A B C$ family proteins, ROS,

DNA damage, cel apoptosis

volume, the injury of heart, liver and kidney

accumulation, ROS generation,

IC50, tumor weight, tumor volume, the

rate of tumor inhibition no heart, liver, and 


\begin{tabular}{|c|c|c|c|c|c|c|c|}
\hline Tumor type & Drug & Structure & In vitro & In vivo & Action results & Mechanism & References \\
\hline & & $\begin{array}{l}\text { nanoliposome } \\
\text { (Dox-NanoLips) }\end{array}$ & & $\begin{array}{l}\text { was intragastrically } \\
\text { administered in mice }\end{array}$ & $\begin{array}{l}\text { the brain-plasma ratio of Dox-nanoLips, } \\
\text { the delivery of DoxnanoLips into the brain, } \\
\text { DTP, DTE, the concentration of Dox in the } \\
\text { left- and right-cerebral cortex and } \\
\text { hippocampus } \\
\downarrow t_{1 / 2}, A^{\prime} C_{0-24} h\end{array}$ & & \\
\hline $\begin{array}{l}\text { The effect of } \\
\text { S-BO on } \\
\text { lymphatic } \\
\text { targeting }\end{array}$ & $\begin{array}{l}\text { Synthetic borneol } \\
\text { (S-BO), } \\
\text { 7-ethyl-10- } \\
\text { hydroxycamptothec }\end{array}$ & $\begin{array}{l}\text { 7-ethyl-10- } \\
\text { hydroxycamptothecin } \\
\text { liposomes (SN-38-Lips) }\end{array}$ & RAW264.7 cells & $\begin{array}{l}\text { Subcutaneously injected } \\
\text { into the right footpad of } \\
\text { KM male mice }\end{array}$ & $\begin{array}{l}\uparrow \text { Residence time, uptake of lymph nodes, } \\
\text { intracellular and the medulla zone of PLNs } \\
\text { fluorescent intensity, } C_{\max }, t_{1 / 2}, M R T_{0-24 h} \\
C L, A \cup C_{0-24 h} \\
\downarrow \text { Injection-site retention } \\
\text { not cause inflammatory reaction of } \\
\text { injection site }\end{array}$ & $\begin{array}{l}\text { Open the barrier gap, } \\
\text { accelerate the } \\
\text { movement of biofilm }\end{array}$ & (64) \\
\hline \multicolumn{8}{|l|}{ DENDRIMERS } \\
\hline Glioma & Doxorubic (DOX) & $\begin{array}{l}\text { A glioma targeted drug } \\
\text { delivery system for DOX } \\
\text { based on BO- and } \\
\text { FA-dual-modified } \\
\text { PAMAM } \\
\text { (FA-BO-PAMAM/DOX) }\end{array}$ & $\begin{array}{l}\text { Human Brain } \\
\text { Microvascular } \\
\text { Endothelial Cells } \\
\text { (HBMEC) and C6 } \\
\text { glioma cells }\end{array}$ & $\begin{array}{l}\text { In-site xenograft glioma } \\
\text { Model by Wistar rats }\end{array}$ & $\begin{array}{l}\uparrow \text { Inhibition of C6 cells, BBB penetration, } \\
\text { C6 cell uptake of DOX, circulating time, } \\
\text { AUC }_{0-\text { inf }} \mathrm{T}_{1 / 2 \beta}, \mathrm{MRT} \text {, the AUC values in } \\
\text { the brain and tumor, the tumor volume } \\
\text { inhibitory ratio (\%), body weight, rat } \\
\text { survival, apoptotic cells in the tumor tissue } \\
\downarrow \text { The cytotoxicity of PAMAM, volume of } \\
\text { distribution (VC), clearance } \\
\text { (CL), cardiotoxicity }\end{array}$ & $\begin{array}{l}\text { Enhance the BBB } \\
\text { penetration }\end{array}$ & $(107,108)$ \\
\hline Glioma & Doxorubic (DOX) & $\begin{array}{l}\text { Borneol physical } \\
\text { combination with } \\
\text { doxorubicin (DOX) loaded } \\
\text { PAMAM dendrimers drug } \\
\text { delivery system modified } \\
\text { with Angiopep-2 } \\
\text { (ANG-PEG-PAMAM) }\end{array}$ & $\begin{array}{l}\text { HBMEC and C6 } \\
\text { glioma cell }\end{array}$ & / & $\begin{array}{l}\uparrow \text { The transportation ratios for } \\
\text { PEG-PAMAM dendrimers and } \\
\text { ANG-PEG-PAMAM dendrimers, inhibition } \\
\text { effect } \\
\downarrow \text { The release rates }\end{array}$ & BBB penetration & (109) \\
\hline Ovarian cancer & Paclitaxel (PTX) & $\begin{array}{l}\text { PTX and Borneol (BNL) } \\
\text { co-loaded in the } \\
\text { fabricated } \\
\text { PEG-PAMAM } \\
\text { nanoparticle (NPs) } \\
\text { (PB/NPs) }\end{array}$ & $\begin{array}{l}\text { Paclitaxel-resistant } \\
\text { ovarian cancer } \\
\text { A2780/PTX cells }\end{array}$ & $\begin{array}{l}\text { BALB/c nude mice } \\
\text { bearing A2780/PTX cell } \\
\text { xenografts }\end{array}$ & $\begin{array}{l}\uparrow \text { Cellular uptake of PEG-PAMAM NPs, } \\
\text { cytotoxicity, mitochondrial depolarization } \\
\text { effects, PTX concentration in tumors, } \\
\text { tumor necrosis } \\
\downarrow \text { Hemolysis rate, drug release, intracellular } \\
\text { ATP level, P-gp, PTX concentration in liver, } \\
\text { tumor growth, tumor size, Ki67 }\end{array}$ & $\begin{array}{l}\text { P-gp, Apoptosis, } \\
\text { mitochondrial function }\end{array}$ & (110) \\
\hline \multicolumn{8}{|c|}{ POLYMERIC MICELLES } \\
\hline $\begin{array}{l}\text { Non-small cell } \\
\text { lung cancer } \\
\text { (NSCLC), } \\
\text { ovarian cancer }\end{array}$ & $\begin{array}{l}\text { Paclitaxel (PTX), } \\
\text { curcumin (CUR) }\end{array}$ & $\begin{array}{l}\text { Polyethylene } \\
\text { glycolpolynorbornene- } \\
\text { thiocresol block } \\
\text { copolymers } \\
\text { (PEG-PNB-TC) loaded } \\
\text { with PTX and CUR }\end{array}$ & $\begin{array}{l}\text { Human non-small } \\
\text { cell lung cancer } \\
\text { A549, cervical } \\
\text { cancer HeLa cells, } \\
\text { multidrug resistant } \\
\text { ovarian cancer cells } \\
\text { (NCl/ADR-RES) }\end{array}$ & / & $\begin{array}{l}\uparrow \text { Blood circulation, drug accumulation, } \\
\text { cell uptake of the PEG-PNB-TC micelles, } \\
\text { cell killing capability } \\
\downarrow \text { Drug release, drug clearance, }\end{array}$ & No description & (111) \\
\hline
\end{tabular}


TABLE 3 | Continued

\begin{tabular}{lll}
\hline Tumor type & Drug & Structure \\
\hline $\begin{array}{l}\text { Cerebrovascular } \\
\text { and cerebral }\end{array}$ & Vinpocetine & $\begin{array}{l}\text { Vinpocetine loaded } \\
\text { degenerative }\end{array}$ \\
$\begin{array}{l}\text { mixed micelles together } \\
\text { diseases }\end{array}$ & & with borneol \\
\end{tabular}

\begin{tabular}{ll} 
In vitro & In vivo \\
\hline & Male SD rats
\end{tabular}

Action results

Mechanism

References

$\uparrow$ Micelle stability and compatibility, drug

loading, drug release, the bioavailability

and the mucosal absorption of VIN, drug

distribution in the brain, brain targeting

$\downarrow$ Absolute bioavailability of VIN in

plasma, Tmax,

Loose the intercelular

(112)

tight junction;

decrease ZO-1 and

F-actin; increase the

number and volume of

pinocytosis vesicles in

BBB cells; inhibit

P-gp, Mdr1a and

Mdr1b

Glioblastoma

Doxorubicin

Conjugated borneol

C6 and HBMEC

DSPE-PEG2000-COOH

cells

The in situ glioblastoma

model build by ICR mice

$\uparrow$ The cellular uptake of DOX-loaded

nanomicelles, micelles' permeability, the

Open the intercellular

tight junction; cell

to synthesize a carrier

DSPE-PEG2000-BO and

loaded with DOX (DOX

BO-PMs)

Glioma

Carmustine Pep-1 and borneol

(CMS)

-bifunctionalized

carmustine-loaded

micelles

Human glioma

BT325 and

HBMECs cells

Orthotopic Luc-BT325

glioma tumor-bearing

Balb/c (nu/nu) nude

(Pep-1/Bor/CMS-M)

mice model

transport ratio of DOX BO-PMs,

apoptosis

anti-proliferation efficacy, the caspase-3

activity, TUNEL-positive cell

$\downarrow$ IC50, C6 cell migration, the time to peak

in brain, tumor volume, hemorrhaging and

necrosis cell

$\uparrow$ The cellular uptake of micelles, the

internalization of Pep-1/Bor/CMS-M, cell

apoptosis, accumulation and the retention

at the brain sites, survival period of mice

$\downarrow$ Cell proliferation, TEER values, tumor

growth

No obvious difference in body weight and

spleen/liver index of mice

\section{LIPOPROTEIN BASED NANOSCALE DRUG DELIVERY SYSTEMS}

\section{Glioma}

Paclitaxel (PTX)

$\mathrm{BOR}$ and PTX

co-encapsulated

lipid-protein

nanocomplex

(BP-liprosome)

$\begin{array}{lll}\text { Glioma } & \text { Paclitaxel (PTX), } & \text { Lipid-albumin } \\ \text { borneol (BOR) } & \text { nanoassemblies } \\ & \text { co-loaded with BOR and } \\ & \text { PTX (BOR/PTX LANs) }\end{array}$

Cryptococcus Itraconazole (ITZ) Bovine serum abumin

nanoparticles (BSA-NPS)

meningitis and

aspergillus brain

abscess nanoparticles (BSA-NPS)

carried with ITZ and

modified with both $\mathrm{BO}$

and $P E G$

(PEG/BO-ITZ-NPS)
C6 glioma cells

Kunming mice bearing a

C6 brain glioma

xenograft

Exhibited a sustained release profile

$\uparrow$ The accumulation of BD-liprosome in the

brain, the PTX concentration in the brain,

the tumor inhibition rates, focal necrosis

and nucleus pycnosis

$\downarrow$ Tumor weight, tumor volume

C6 glioma cells Kunming mice bearing a $\quad$ The cellular uptake of PTX, the uptake

C6 brain glioma

and the internalization of LANs,

distribution of LANs in tumor

xenograft

$\downarrow \mathrm{C}_{50}, \mathrm{P}$-gp, ATP, liver toxicity

TThe cellular uptake of nanoparticles, NPs'

permeation through BBB, plasma level,

$t_{1 / 2 \beta}$, mean residence time (MRT), $A \cup C_{0-t}$,

the distribution of nanoparticles in brain

$\downarrow$ The release of ITZ, clearance (CL)
P-gp, clathrin- and

Apoptosis

P-gosome/lysosome-

associated

pathways

Clathrin-mediated

pathway, improved

BBB penetration

efficiency 
drugs. Borneol is always used as an adjuvant in combination with other drugs to reduce the dosage of other drugs, increase their therapeutic effect, and decrease drug side effects (118). In recent years, many studies have shown that borneol often served as an antitumor chemotherapeutic sensitizer works along with the chemotherapeutic drugs to promote anticancer effect by increasing the level of reactive oxygen species (ROS) (119), arresting cell cycle (120), and regulating the expression of proapoptotic MAPK family member proteins and PI3K/Akt pathway proteins (121). However, the volatility of borneol makes it extremely unstable during preparation and storage. In addition, the poor water solubility of NB is not conducive to blood circulation, which greatly limits the effective delivery to the treatment site and greatly reduces its therapeutic effect. The progress of nanotechnology in the field of biomedicine undoubtedly provides a novel method for expanding and improving the medicinal value of natural borneol (122). Nanotechnology has unique advantages in improving the stability, biocompatibility, and absorption of drugs, and is increasingly being used to design new delivery systems for drugs. Therefore, the introduction of borneol into the nanocarrier is expected to increase the transmembrane absorption and the delivery of drugs into tumor cells.

Yuan et al. (105) used Tween 80 as surfactant, olive oil as an oil phase, and incorporated natural borneol into the hydrophobic core of NPs so that the hydrophilic phase extended outward into the hydrophilic environment. These alterations greatly improved the water solubility of natural borneol and prevented the volatilization of the NPs during the drug delivery, which induced NB crystals were easy to be dispersed in the nano system of natural borneol NPs (NBNPs) after nanolization. MTT results indicated that the inhibition efficiency of NBNPs + gefitinib (GFT) was considerably higher than that of free NBNPs and free GFT. The combination indices (CI) value suggesting that the NBNPs+ GFT (0.931) group exhibits a synergistic effect, while the NB + GFT (1.046) group shows a slight additive effect. In addition, NBNPs exerted excellent selectivity between A549 and normal lung fibroblast cells WI38 cells, exhibiting great targeting. These results demonstrated that nanolization of NB improved the antitumor activity and sensitization to GFT than free NB, owing to how some moieties of NBNPs had been exposed after nanolization and then enhanced the cellular uptake of GFT. The mechanisms of NBNPs enhanced GFT therapy in A549 cells by arresting the cell cycle in the Sub-G1 phase, increasing ROS, suppressing DNA synthesis, and promoting cell apoptosis. Proteomics results revealed that further mechanism was NBNPs inhibiting EGFR-associated protein EHD1 to cascade apoptosisassociated signaling pathway (Figure 3). In another study, Han et al. (109) fabricated a poly amido amine (PAMAM) dendrimer loaded with doxorubicin (DOX) modified with Angiopep-2 (ANG/PAMNA/DOX) because DOX cannot pass through the $\mathrm{BBB}$ in the body. Angiopep-2 modification could enhance the affinity between the dendrimers and finally increase the cell uptake and boost the antitumor ability. The result showed that borneol co-incubation significantly enhanced the transportation ratios of ANG/PAMNA/DOX mainly caused by the promotion effect of borneol for opening tight junctions of the BBB. Moreover, the self-assembled bottlebrush polyethylene glycolpolynorbornene-thiocresol block copolymers (PEG-PNB-TC) with paclitaxel (PTX) coloaded into their hydrophobic core could be efficiently taken up by cells in vitro and induced comparable cytotoxicity to the cancer cells. Compared with commercial PTX formulation (Taxol), the PTX-loaded PEG-PNB-TC micelles enhanced in vitro cellular uptake and comparable cytotoxicity, which is related to PEG-PNB-TC micelles that could be efficiently internalized by cancer cells most likely as an intact entity. PEGPNB-TC polymers were safer and more biocompatible than Cremophor EL, which is the surfactant used in Taxol. In addition, PEG-PNB-TC micelles that could coload curcumin showed a synergistic effect to overcome the drug resistance at a high ratio of Cur/PTX, whereas the lower Cru/PTX ratio showed an additive effect. It provides a strategy for current cancer treatments in two ways: (i) ensuring to adjust multiple drugs with different ratios and higher drug loading; and (ii) the clinically used or well-investigated combination drugs could be directly applied to the PEG-PNB-TC micelles without further adjustment of drug ratios (111). Zou et al., finding that ginsenoside Rh2 lipid nanoparticles with the assistance of borneol has better effects with increased the solubility of ginsenoside Rh2, slowed the drug release, reduced the IC50 of C6 cells in a concentrationdependent manner, and improved the antitumor effect. The oral bioavailability of ginsenoside $\mathrm{Rh} 2$ increased after being loaded into lipid nanoparticles by increasing the residence time through the adhesion of the lipid layer and contact area. The specific antitumor mechanism is not described (100). It has been reported that lipid-albumin nano assemblies coloaded with borneol and paclitaxel (BOR/PTX LANs) enhanced the cytotoxicity and reversed MDR in C6 glioma cells. The BOR/PTX LANs displayed higher cytotoxicity against $\mathrm{C} 6$ glioma cells. However, the addition of free cyclosporine A (CsA) or BOR along with BOR/PTX LANs did not significantly increase PTX uptake, indicating that BOR/PTX LANS had sufficient ability for PTX to inhibit P-gp efflux. It was proved that the cellular uptake of BOR/PTX LANs by $\mathrm{C} 6$ cells was contributed for two reasons. First, the BOR/PTX LANs intracellular released BOR inhibits P-gp efflux. Second, endocytosis of BOR/ PTX LANs consumed ATP, which could reduce the activity of P-gp. Finally, the composition of BOR/PTX LANS was like the lipids and proteins of the cell membrane, which may have a higher affinity with the cell membrane of tumor cells to increase the cellular uptake, thus improving cell cytotoxicity. Additionally, the distribution of drugs in the liver was decreased, which weakened the side effects of drugs (116).

\section{Reduced the Toxicity}

Yuan et al. (105) found that NBNPs + GFT treatment not only exhibits a higher tumor inhibitory effect than $\mathrm{NB}+$ GFT or GFT treatment, but also showed a higher survival rate. The survival rate of $\mathrm{NB}+\mathrm{GFT}$ and GFT groups was 85.9 and $75.0 \%$, respectively, and $100 \%$ in the NBNPs + GFT group without significant body weight loss. The histopathological analysis indicated that the NBNPs + GFT group without evident pathological changes were caused in the heart, liver, spleen, lung, 


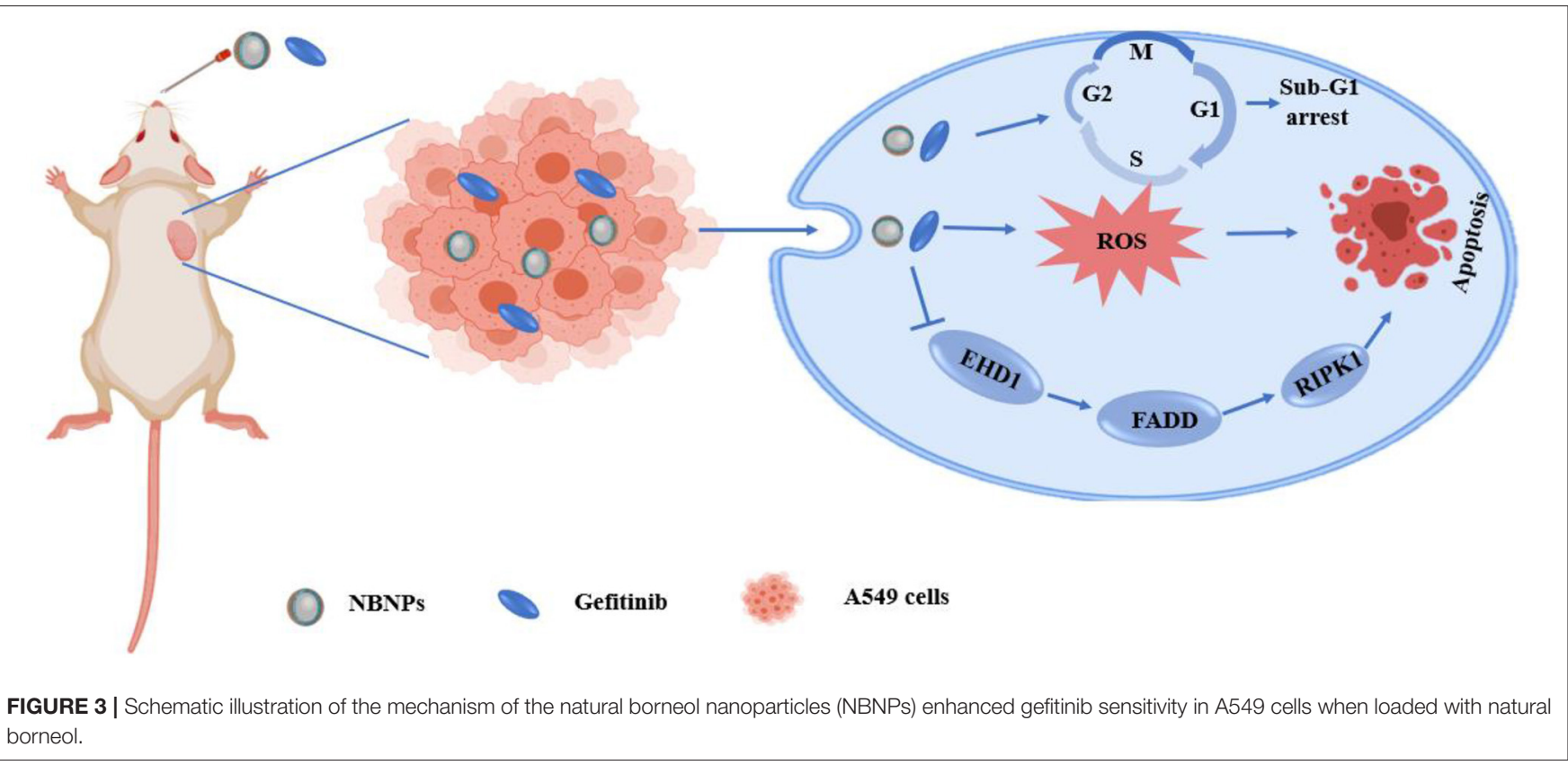

and kidney owing to the accumulation of NBNPs in the liver, spleen, and lung was gradually decreased as time went on to $24 \mathrm{~h}$. In addition, the blood biochemistry indices effectively recovered the hematological indices, reflecting the physiological function of the kidney, liver, and lipid metabolism including blood urea nitrogen (BUN), aspartate aminotransferase (AST), total protein (TP), globulin (GLB), albumin/globulin ratio (A/G), and highdensity lipoprotein cholesterol (HDL-C) at the normal level. These indices of the tumor-bearing mice have been changed to vary degrees compared to the healthy nude mice without tumor. These findings suggested that the combination therapy alleviated the tumor-associated toxicity and recovered the function of the major organs. Thus, NBNPs combined with GFT enhanced antitumor effect against NSCLC and without causing evident systemic toxicity. Effective targeting drug delivery system for glioma treatment is still greatly challenged by the existence of the $\mathrm{BBB}$ and the intracranial overspreading of the antitumor drug. If the drug reaches the non-glioma site after entering the brain, the concentration of the drug in the glioma site will decrease, and it may also cause more serious central system side effects. Poly amido amine (PHAMA) is an excellent carrier for brain drug delivery systems, which is beneficial to drug delivery and structural modification. But PAMAM with a positive charge usually has hemolytic and cytotoxicity (123). In previous studies, biocompatible polyethylene glycol (PEG) or lauroyl chloride is usually modified into a PAMAM dendrimer to reduce the toxicity induced by naked amine termination. However, these single modified vectors cannot effectively penetrate the BBB (124). A dual-functional glioma targeting delivery of doxorubicin was designed by the poly amido amine (PAMAM G5) dendrimer, modified with folic acid (FA) and borneol (BO) (FA-BOPAMAM/DOX). Borneol modification reduced the potential toxicity of the PAMAM surface by reducing the amino groups on the surface of PAMAM. Furthermore, borneol modification increased the transport across the BBB ratio by 2 -fold. Compared with the DOX alone, FA-BO-PAMAM/DOX increased the accumulation of DOX in tumor tissue, which means decreasing the drug in other sites. The fluctuation in animal body weight can reflect the side effects of drugs. The body weight of rats showed a slight increase at the early stage of tumor growth, compared with DOX alone. The cardiac toxicity was reduced because FA-BO-PAMAM/DOX effectively delivered DOX to the target site and decreased its content in the heart. At the same time, the median survival time of xenograft rats (28 days) was significantly prolonged compared to free DOX (18 days). Thus, modification with borneol not only decreased the cytotoxicity of PAMAM itself, but also facilitate DOX passage through the BBB easily $(107,108)$. Carmustine (CMS) is a commonly used drug for clinical treatment of glioma, with a short half-life of 15$30 \mathrm{~min}$ and lack of selectivity for tumor cells resulting in blood toxicity, bone marrow suppression, liver, and kidney injury. Reports suggest that borneol as a $\mathrm{BBB}$ permeation enhancer effectively improves the intracerebral delivery of nanodrugs. Guo et al. (114) developed Pep-1 and borneol-biofunctionalized CMS-loaded micelles (Pep-1/Bor/CMS-M), which is capable of penetrating the $\mathrm{BBB}$ and targeting glioma cells actively, thereby circumventing its limitations. Compared to CMS-M, Bor/CMS-M entered the cells more easily, which is probably related to how borneol modification reduced the integrity of the junction between endothelial cells, thereby facilitating the entry of particles into the BBB. Moreover, Pep-1/Bor/CMS-M did not lead to a significant decrease in body weight after five injections and obvious difference in the spleen/liver index and liver kidney function, exhibiting the longest survival period and low systemic toxicity in treating orthotopic glioma tumor-bearing nude mice. Natural borneol nanoparticles (NBNPs) combined with GFT 
not only inhibited the tumor growth, but also alleviated the heart, liver, and kidney damage and exhibited no obvious toxicity in vivo $(101,102)$.

\section{Inhibited Tumor Metastasis}

Approximately $0.5 \%$ of all glioblastoma patients suffer extracranial metastases. Meng et al. (113) designed a drug delivery system borneol-modified DSPE-PEG2000-BO loaded with doxorubicin (DOX-BO-PMs). The results demonstrated that no obvious metastases occurred in the lung tissues. In addition, vascular infiltration was found obviously in the DOX solution and DOX PMs groups, whereas no abnormalities were observed in the tissues in the DOX-BO-PMs group. On the other hand, the DOX solution and DOX PMs groups found a significant liver metastasis, while no liver metastasis was observed in the DOX BO-PMs group. These results indicated that DOX BO-PMs exhibited a significant suppressive effect on tumor metastasis. In addition, DOX-BO-PMs enhanced the antitumor effect of DOX by inhibiting cell migration, increasing caspase 3 , and inducing cell apoptosis effectively. Furthermore, DOX-BO-PMs group did not show remarkable side effects on body weight maintenance of tumor-bearing mice. DOX-BO-PMs significantly enhanced the transport efficiency of DOX across the BBB and exhibited a quick accumulation in the brain tissues to enhance the antitumor effect of DOX. Although the researchers did not explain the mechanism of antimetastatic efficacy of DOX-BO-PMs, we speculate that the effect of inhibiting metastasis is related to its enhanced antitumor effect.

\section{Sensitizing and Reversing the MDR}

In recent years, nanotechnology-based chemotherapy has exerted potential in cancer treatment. However, MDR limits the efficacy of chemotherapy. Nanocarriers, such as liposomes, lipid nanoparticles, polymeric micelles, and microemulsions have gained much attention to overcome MDR. Although they can improve the solubility of drugs and act as the intracellular drug reservoirs after entering the tumor cells (125). However, most of the free drugs were still expelled by the P-gp in tumor cells (126). Therefore, it is effective to overcome MDR of the tumor cells by co-encapsulation of the P-gp inhibitors and the anti-tumor drugs using a nanodrug delivery system. In addition, P-gp has been an important mechanism of multidrug resistance. It has been reported that overexpression of P-gp in tumor cells decreases the intracellular accumulation of DOX, paclitaxel, and cisplatin, which results in lower therapeutic efficacy. Therefore, suppressing P-gp expression has become an effective way to enhance chemotherapy efficacy and reverse chemoresistance (127). Borneol is bicyclic monoterpenoid alcohol with an antibacterial and anti-inflammatory effect. Furthermore, previous studies confirmed the role of penetration enhancer to improve oral bioavailability and increase the drug distribution in some tissues (37-39). Particularly, borneol has been reportedly used as a biologically active natural product in cell signal transduction, such as elevate the level of ROS, arrest the cell cycle, and regulate the apoptosis signal pathway (101). Furthermore, borneol can participate in reversing multidrug resistance by inhibiting the expression of P-gp (128). Therefore, the use of borneol to enhance membrane permeability and inhibit the expression of efflux proteins to design new nanocarriers loaded with chemotherapeutics may play an unexpected role in overcoming multidrug resistance.

Zeng et al. (99) fabricated novel cancer-targeted drug carrier selenium NPs (SeNPs) combined with borneol and galactosamine (GAL) (GAL/Bor@SeNPs). Borneol-modified SeNPs can significantly improve the stability of SeNPs and their anticancer activity. Nanoparticles with a diameter of $<200 \mathrm{~nm}$ are more likely to enter the cell and increase the selectivity of the drug in the cancer cell. The use of borneol can significantly reduce the particle diameter of SeNPs. MTT assay results showed that GAL/Bor@SeNPs reduced the toxicity on L02 cells and improved the activity of drug-resistant hepatocellular carcinoma cells (R-HepG2) cells. GAL/Bor@SeNPs inhibited the expression levels of $\mathrm{ABC}$ family proteins (ABCB1, $\mathrm{ABCC}$, and ABCG2) in R-HepG2 cells in a dose-dependent manner, is consistent with borneol could participate in reversing multidrug resistance by inhibiting the expression of P-gp. The further mechanism was that GAL and borneol provide a rational strategy for the construction of a functional nanosystem to reverse multidrug-resistant cancers by inhibiting the expression of ATPbinding cassette family proteins, inducing cell apoptosis through ROS-activated $\mathrm{p} 53$ phosphorylation, mitogen-activated protein kinase (MAPK), and protein kinase B (AKT) pathways. The disadvantages of poor water solubility and unstable distribution of borneol in the body limit its application as a sensitizer. Cheng et al. (101) prepared natural borneol into nanoparticles (NBNPs) with borneol to prevent sublimation, thereby improving the stability of borneol. Compared with NB, NBNPs inhibited A549 cell proliferation by increasing the levels of ROS and DNA damage leading to cell apoptosis. Moreover, NBNPs enhanced the sensitivity of GFT by increasing the level of ROS and DNA damage, arresting the sub-G1 phase, leading to cell apoptosis furtherly. In another study, the PLGA loaded with d-borneol NPs (PLGA@NB) were administrated with doxorubicin (DOX) to A549 cells. The results revealed that PLGA@NB+DOX decrease the IC50 from 0.8 to $0.08 \mu \mathrm{m}$, and the antitumor activity increased by 10 -fold. Moreover, the PLGA@NB+DOX improved the cellular uptake by 1.5fold, increased the level of ROS to $169 \%$, and remained above $165 \%$ within $2 \mathrm{~h}$. The mechanism of enhanced the sensitivity of DOX was PLGA@NB+DOX elevating the ROS level and inducing cell apoptosis, which was consistent with the previous study (102). Zou et al. (110) coloaded paclitaxel (PTX) and borneol (BNL), a natural compound with P-gp inhibition effect confirmed in intestinal absorption, in fabricated PEGPAMAM NPs (PB/NPs) using a one-step nanoprecipitation method and reserved the MDR of paclitaxel-resistant ovarian cancer A2780/PTX cells in vitro and in vivo. The combination of BNL could remarkably increase PTX cellular uptake in A2780/PTX cells. BNL was liable to bind with P-gp, confirmed by molecular docking. The docking calculation showed that BNL and verapamil were docked in P-gp molecule with a similar binding domain, in which most binding sites of the two drugs had a great deal of overlap. The potential MDR 
reversal mechanisms were co-delivery of PTX and BNL by PEG-PAMAM NPs would inhibit P-gp expression, enhanced mitochondrial depolarization effects, inhibiting intracellular ATP production to interfere with the mitochondrial function, promote cell apoptosis.

\section{Enhanced Targeting}

The BBB acts as a physical barrier to prevent most chemotherapeutic drugs from crossing into the brain, which restricts antitumor effects. Borneol is a highly lipid-soluble bicyclic terpene, which can facilitate the distribution of central nervous system drugs in the brain via opening BBB. Previous studies have confirmed the mechanism involved in open the intercellular tight junctions, inhibit the P-gp, enhance pinocytosis in the $\mathrm{BBB}$ cells and improve the permeation of drugs across the BBB $(44,45)$. In the past few decades, targeted nanodrug delivery systems, such as nanoparticle, liposome, and dendrimer, have revolutionized the diagnosis and treatment of brain tumors. These nanocarriers still have some limitations, such as the low drug loading, premature release of the drug into the blood circulation, without active targeting, and poor permeability to cross the BBB (129). In addition, simple nanocarriers are quickly swallowed by macrophages in the reticuloendothelial system after intravenous injection, and many of them are targeted to the liver and spleen, leading to low brain targeting efficiency (130). Based on the above advantages of borneol, the modification of borneol in nanocarrier has great potential to enhance brain targeting.

The poor $\mathrm{BBB}$ penetration and low accumulation of therapeutic drugs at tumor sites are the major obstacles to achieving success glioma treatment. A previous study (98) investigated the efficiency of CGKRK peptide (a ligand of the heparan sulfate, which is overexpressed in glioma cells) modified paclitaxel prodrug self-assembled redox-responsive NPs (CGKRK-PSNPs) combined with borneol in glioma treatment. CGKRK was proved could target tumor cells and tumor neovascular through binding to the specific receptor heparan sulfate. PSNPs [paclitaxel prodrug (PTX-SS-C18) conjugate self-assembled nanoparticles] was used to accurately trigger-release PTX in tumor cells by the intracellular GSH. Borneol was intragastrically administrated for $0.5 \mathrm{~h}$ in advance to open the tight junctions of the BBB reversibly, and then CGKRK-PSNPs were injected via the tail vein and penetrated across the BBB to accumulate at tumor sites with the assistance of borneol active glioma target ability. The penetration efficiency of CGKRK-PSNPs with the assistance of borneol increased to $23.85 \%$ compared to without borneol $(18.38 \%)$ in vitro BBB model established through BCEC cells. The images of ex vivo brains and the semiquantitative results also demonstrated that CGKRK-PSNPs combined with borneol exhibited the highest accumulation than other groups. These findings suggested that CGKRK-PSNPs significantly enhance the active tumor targeting efficiency owing to the CGKRK peptide-mediated endocytosis and $\mathrm{BBB}$ penetration ability of borneol (Figure 4). Brucea javanica oil emulsion is used to treat brain glioma by injection. The emulsion is a multiphase kinetic unstable dispersion system with a large diameter, easy demulsification and delamination, and a low concentration cross into the brain limits its clinical application. Li and Lv et al. $(103,104)$ successfully prepared borneol and Brucea javanica oil nano emulsion (BBNE) with a small particle diameter, high stability, and large drug loading. Results indicating that BBNE not only improved the stability of the drug, but also inhibited tumor growth. The mechanism may be related to borneol promoting the transport of drugs across to the $\mathrm{BBB}$, increasing drug brain targeting, and improving drug distribution in the tumor tissue. Wu et al. (106) fabricated doxorubicin hydrochloride nanoliposomes (Dox-Nanolips). Coadministrated with borneol quickly enhanced the distribution of Dox-nanoLips to other tissues or organs with the increased value of the distribution phase rate constant $(\alpha)$, indicating that borneol may be beneficial to promote the brain targeting of Dox-nanoLips. Borneol increased the Dox concentrations of the Dox-nanoLips group in the cerebral cortex and hippocampus, while no change in the distribution of left and right-brain regions, indicating borneol has a specific targeting effect on DoxnanoLips entering the cortex and hippocampus. The stronger red fluorescent signal of the borneol co-administration group was observed in the cerebral cortex, CA3, and dentate gyrus (DG) of the hippocampal region compared with Dox-nanoLips group, the GFAP (indicated astrocytes) fluorescent mainly appeared in the DG region, but the red fluorescent of Dox in the borneol co-administration group did not co-localize with the astrocytes in the merge images of the DG region. Thus, compared with Dox-nanoLips alone, Dox-nanoLips coadminister with borneol can directly across the BBB into the brain parenchyma by borneol opening the BBB tight junction, and then taken up into the neuronal cells bypassing astrocyte, which was beneficial to the higher neuronal targeting in the cerebral cortex, CA3 and DG region of the hippocampus. PTX cannot transport across the BBB and reach therapeutic concentrations in the brain tissue. Although the lipid-protein nanocomplex (liposome) was successfully prepared from egg yolk lecithin (PL 100M) and bovine serum albumin (BSA), the PTX transport across the $\mathrm{BBB}$ enhanced and systemic toxicity reduced compared to that of PTX solution. However, the brain tissue accumulation of PTX was still relatively low. Encouraged by the high potential of borneol as a promoter for drug transport across the $\mathrm{BBB}$, a borneol (BOR) and paclitaxel (PTX) encapsulated lipid-protein nanocomplex (BP-liposome) was prepared. The cumulative release of PTX was lower than that of BOR in BP-liposome at all time points, which induce the earlier release of BOR to improve the permeability of the $\mathrm{BBB}$, and subsequently increase the transport of PTX to the brain. BP-liposome enhanced the brain targeting of PTX by increased the accumulation of PTX in the brain. This is probably due to the particle characteristics of the BP-liposome and the synergistic effect of BOR. First, borneol accelerated the transport of drugs through intercellular channels by reducing the level of tight junction proteins in the intercellular junctions. Second, borneol could be bound to a site on the cell membrane or be absorbed to the membrane surface to improve the membrane fluidity of the epithelium. Consequently, the orderly arrangement of membrane phospholipid molecular chains was increased and 


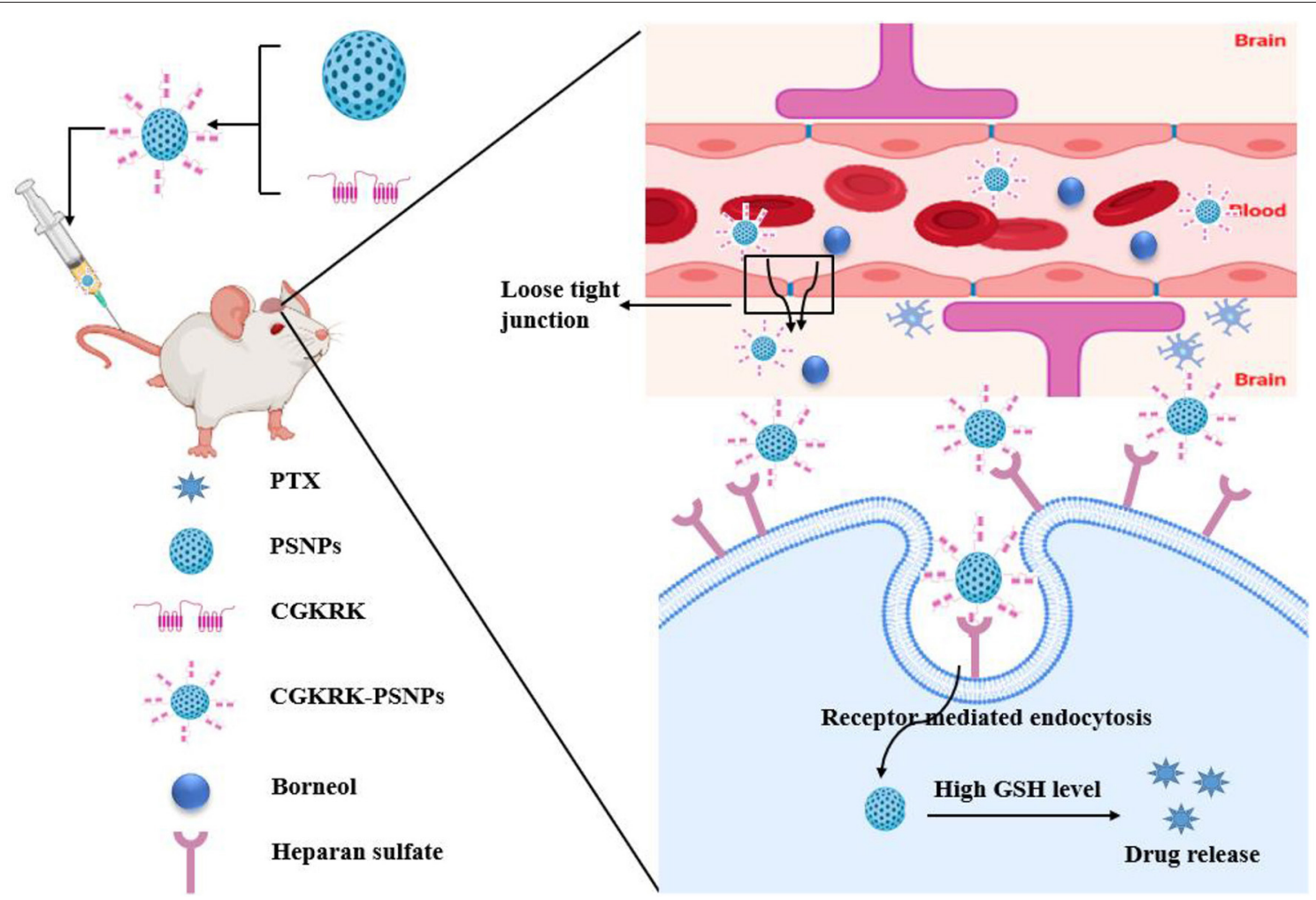

FIGURE 4 | Schematic illustration of the application of the borneol combined CGKRK peptide modified paclitaxel prodrug self-assembled redox-responsive nanoparticles (CGKRK-PSNPs) for brain targeting in glioma treatment.

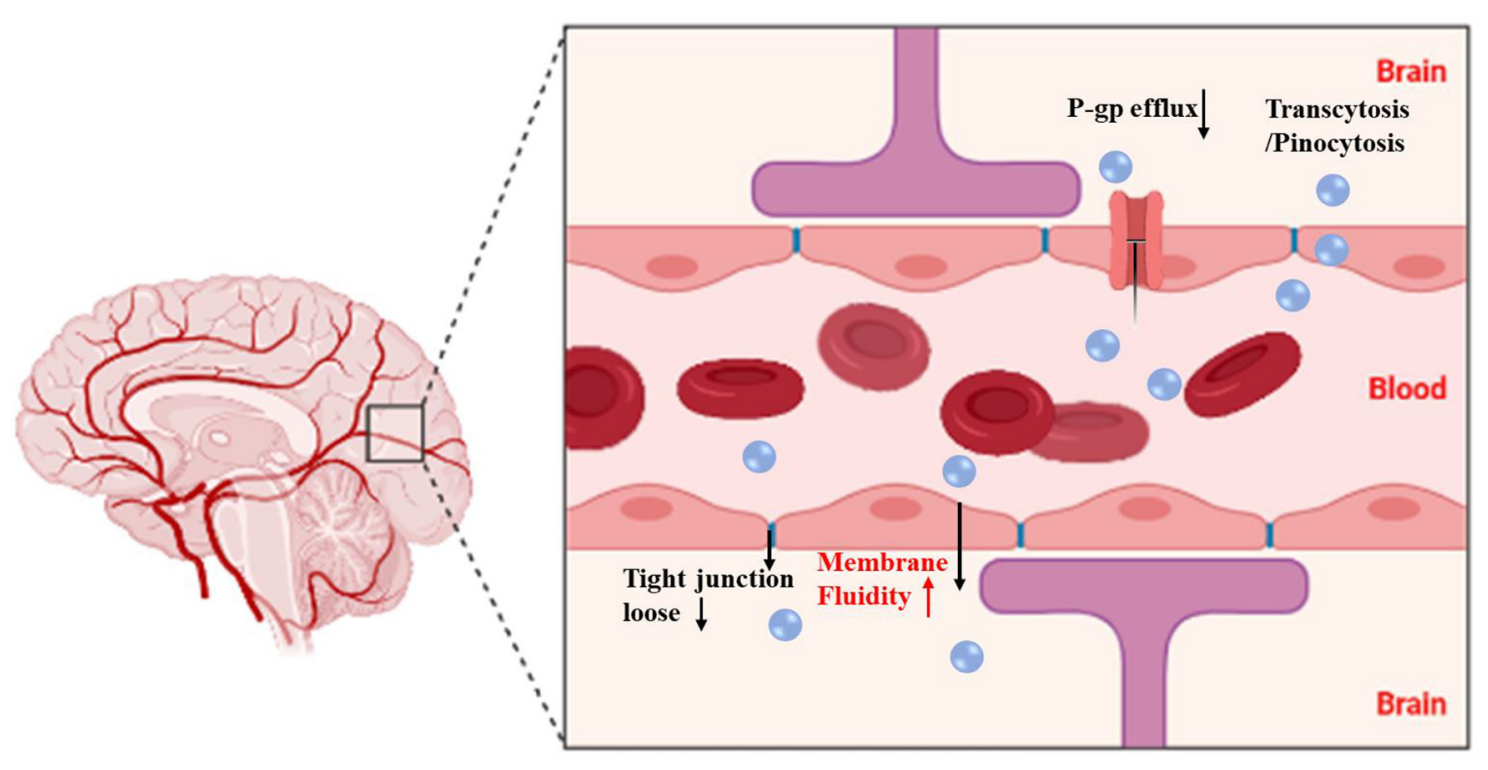

FIGURE 5 | Schematic illustration of BP-liposome transport of paclitaxel (PTX) across the blood-brain barrier (BBB) and improvement of the anti-glioma effect of PTX. The figure was created by BioRender, https://app.biorender.com/.

the collision of drugs with phospholipid molecules was reduced, which promoted drug penetration through the cell membrane. Third, borneol inhibited P-gp expression, which inhibited drug efflux and enhanced the transport of drugs across the BBB (115) (Figure 5). Bovine serum albumin nanoparticles (BSANPs) served as one of the most appropriate carriers for drug 


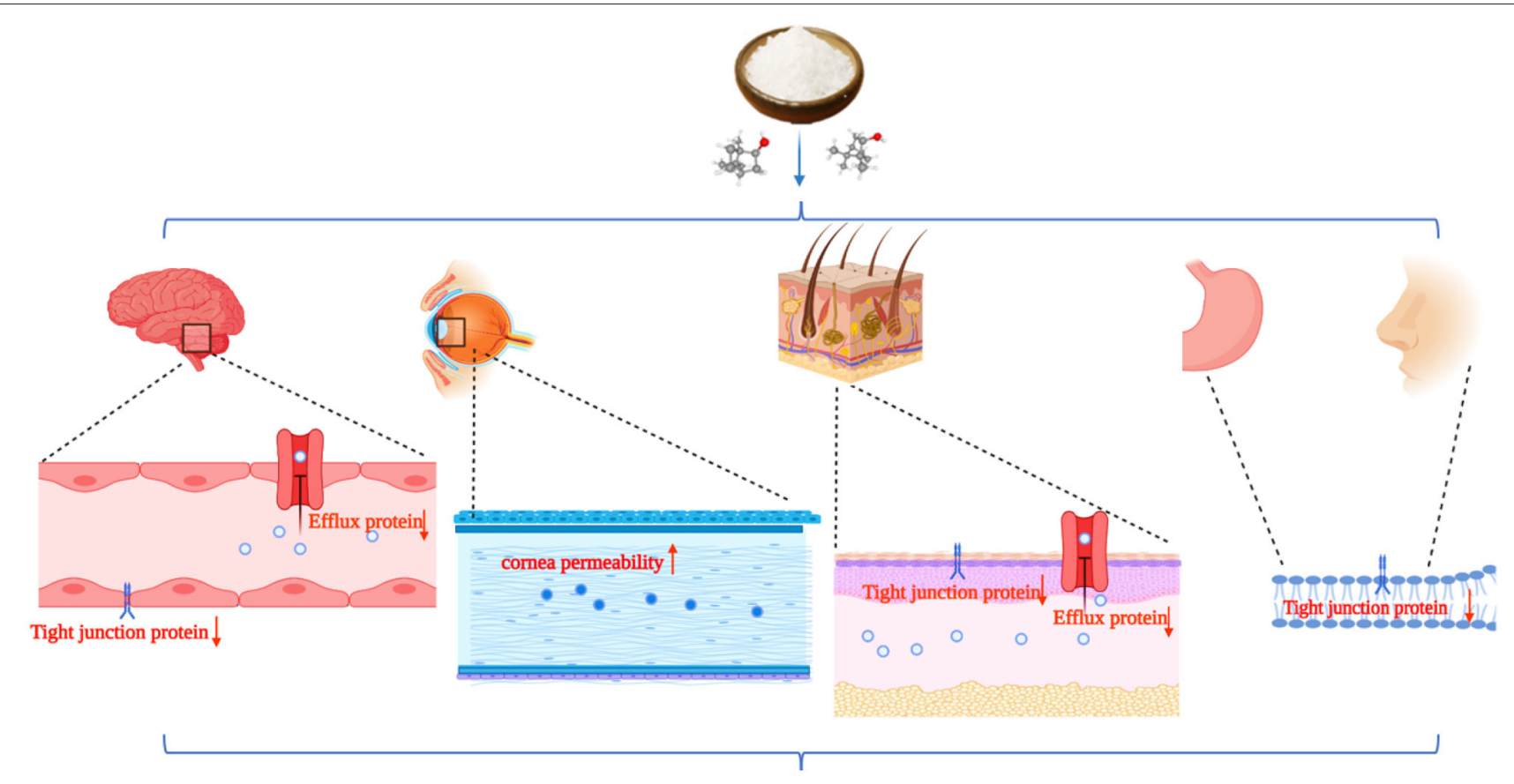

Natural penetration enhancer

FIGURE 6 | The penetration promoting effect of borneol is mainly reflected in promoting drug penetration through the skin, gastrointestinal mucosa, nasal mucosa, corneal, and the blood-brain barrier (BBB). The main mechanisms involved changes in the arrangement of lipid molecules and increases in their fluidity, improved mucosal cell permeability, increased paracellular and intercellular transport, destruction of the tight junction proteins, opened the BBB, and inhibited the expression of drug-resistant proteins, such as multidrug resistance mutation 1 (MDR1) and P-glycoprotein (P-gp), to reduce the drug efflux. The figure was created by BioRender, https://app.biorender.com/.

delivery since it is biocompatible, biodegradable, non-toxic, and non-immunogenic. Based on this, a brain targeting drug delivery system for carrying ITZ was designed based on BSA-NPs, modified with both borneol (BO) and PEG (PEG/BO-ITZNPs). Modification of BO endowed ITZ-NPs with the brain targeting attributes, resulting in an exacerbated quantity of ITZ in the brain, this is attributed to borneol modification regulated membrane permeability, improved the mobility of phospholipid molecules, and inhibited P-gp mediated efflux, thereby increasing $\mathrm{BBB}$ penetration efficiency to enhance brain targeting and extend the retention time of the drug. Thus, $\mathrm{BO}$ and PEG dual modified BSA nanoparticles may potentially serve as an ITZ vehicle for brain targeting (117). The BBB represents a huge obstacle for the therapy of central nervous system related diseases. Polymeric micelles have many advantages for brain targeting by oral delivery, but the stability and targeting efficiency needs to be improved. How to bypass the BBB barrier via the oral route to achieve better brain targeting is a problem that must be solved. Ding et al. (112) investigated whether the oral absorption and brain distribution of vinpocetine (VIN) could be significantly improved by P123-based mixed micelles in combination with borneol. Compared to the micelles only group, VIN was absorbed faster after co-administration with borneol, indicating borneol enhanced brain targeting effect of VIN. In addition, the brain $\mathrm{Ce}\left[\left(\mathrm{C}_{\max }\right)_{\text {brain }} /\left(\mathrm{C}_{\max }\right)_{\text {plasma }}\right]$ was increased after peroral administration of P123 based mixed micelle, which enhanced passive brain-targeting. Taken together, the possible mechanism of enhanced peroral absorption and brain targeting of the VIN was the combination of the P123 passive targeting effect based on mixed micelles and the active targeting of borneol. The lymphatic system has become an important target and drug delivery route for preferential therapeutic. Ye et al. (64) found that synthetic borneol (S-BO) enhanced the lymphatic targeting of 7-ethyl-10-hydroxycamptothecin liposomes (SN-38-Lips) in the paracortex and medulla of the popliteal lymph node (PLN) cytoplasmic via increasing cellular uptake of lymphocyte and macrophages in the lymph node, especially through phagocytosis of macrophages.

\section{Summary}

The use of nanocarriers modified by non-toxic and efficient natural products to enhance the therapy efficiency of traditional antitumor drugs is an innovative strategy in recent years. The above results revealed that borneol modification increased the cellular uptake of co-loaded drugs by inhibiting the efflux protein P-gp and then boosting the antitumor effect by arresting the cell cycle, increasing ROS, suppressing DNA synthesis, and promoting cell apoptosis. Borneol modification can reduce the toxicity of some nanocarrier material like PAMAM and increase the accumulation of drugs in the 


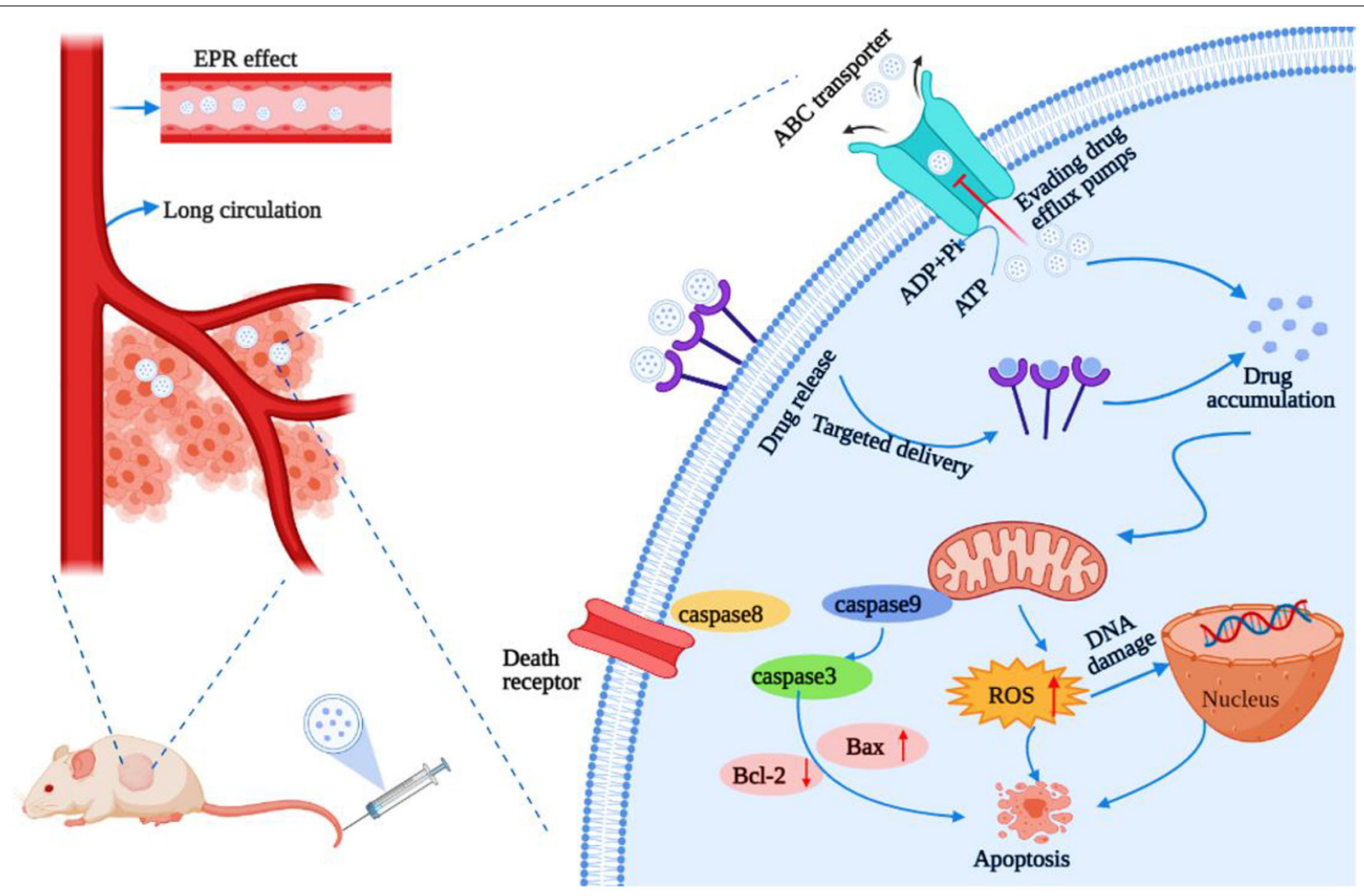

FIGURE 7 | Main role and mechanism of borneol modified nanoparticle-based drug delivery platforms for overcoming multidrug resistance (MDR). The figure was created by BioRender, https://app.biorender.com/.

tumor site, thereby reducing the toxicity of other organs, such as the heart and liver, and prolong survival time. The above results also revealed that borneol modified exhibited a better multidrug resistance reversal effect, the possible involved mechanisms including increasing the accumulation of drugs in tumor site by inhibiting P-gp induces drug efflux, blocking the cell cycle, increasing the level of ROS, and promoting cell apoptosis. Finally, borneol modification enhances the targeting, especially in the brain. Borneol served as a promoter for drug transport across the BBB by loosening the tight junction, improving the membrane fluidity of the epithelium, and inhibiting P-gp mediated drug efflux. Furthermore, nanolization of borneol not only improves its water solubility, but also prevents volatilization loss during the administration process, overcomes poor drug stability, and exhibits stronger targeting and cytotoxicity. In addition, the modification of the small molecule borneol also simplifies the synthesis process and reduces the synthesis cost. Therefore, borneol has potential advantages in the construction of candidate nanocarriers material to enhance the targeting effect, overcome multidrug resistance, and reduce the toxicity of drugs or nanocarrier material.

\section{CONCLUSIONS}

Borneol is a courier herb that has been used for thousands of years to facilitate the transport of co-administered drugs.
The mechanisms of borneol as a permeation enhancer for delivering drugs across the BBB, corneal, skin, gastrointestinal, and nasal mucosal barriers where borneol could change the close connection between the epithelial cells, accelerate the transportation of drugs through the intercellular passage, increase the number and volume of pinocytosis vesicles in BBB cells, improve cell membrane permeability, change the integrity of the lipid cell membrane, decrease the collision and the resistance between phospholipid molecules, increase their fluidity, significantly inhibit the activity of drug resistance proteins such as MDR1 and P-gp, and then accelerated the transportation of drugs (Figure 6).

Borneol modified different types of nanocarriers, such as NPs, nanoemulsions, liposomes, dendrimers, polymer micelles, and lipoprotein nanocomposites applied in the drug delivery systems for treating solid tumors (lung, breast, brain, and liver cancer) could increase the solubility of drugs, enhance cellular uptake and cell cytotoxicity, decrease nanocarrier toxicity, reduce organ toxicity, and overcome MDR. Modified borneol could also enhance brain targeting, lymphatic targeting, drug distribution, and the antitumor effect. The main mechanisms include regulating the protein responsible for transporting drugs from the cell membrane and inhibiting their overexpression, including the $\mathrm{ABC}$ membrane transporter superfamily MRP1/ABCC1 and $\mathrm{P}$-gp/ABCB1. Consequently, drug efflux is inhibited, drug entry into cells is promoted, and the accumulation and redistribution of therapeutic drugs at tumor target sites are increased, which, 
together, lead to the activation of signaling pathways, including those involved in ROS, DNA damage, and apoptosis (Figure 7).

\section{FUTURE PERSPECTIVES}

The above current studies strongly suggest that borneol modification nanocarriers have a promising future in the field of solid tumor treatment although the current research mostly stayed at the cell lines or the rodent-based models. The huge gap between the preclinical studies and human results remains to be filled. Furthermore, the safety of nanodrug accumulation in unwanted tissues and organs and the uncertain safety concerns of some nanomaterials need to be determined. The rational combination of multiple drugs with different modes of action is also a challenge, as are issues with manufacturing scale and practice, including reproducibility, non-uniform diameter, irregular structure/shape, sterilization, and storage for mass production (131). In addition, the relationship between the amount-time-effect and the effect of the immune system following borneol administration remains to be explored. Of course, with the in-depth understanding of tumor biology, the behavior of NPs in the body, the pharmacological mechanism of antitumor drugs, and the continuous discovery and clarification of the mechanism of herbs active ingredients, it is believed that the combination of traditional Chinese herbs and chemotherapeutic drugs in nanocarriers will bring surprises

\section{REFERENCES}

1. Yang Y, Tong C, Zhong J, Huang R, Tan W, Tan Z. An effective thermal therapy against cancer using an E-jet 3D-printing method to prepare implantable magnetocaloric mats. J Biomed Mater Res B Appl Biomater. (2018) 106:1827-41. doi: 10.1002/jbm.b.33992

2. Umelo IA, Costanza B, Castronovo V. Innovative methods for biomarker discovery in the evaluation and development of cancer precision therapies. Cancer Metastasis Rev. (2018) 37:125-45. doi: 10.1007/s10555-017-9710-0

3. Marusyk A, Almendro V, Polyak K. Intra-tumour heterogeneity: a looking glass for cancer? Nat Rev Cancer. (2012) 12:323-34. doi: 10.1038/nrc3261

4. Kunjachan S, Rychlik B, Storm G, Kiessling F, Lammers T. Multidrug resistance: physiological principles and nanomedical solutions. Adv Drug Deliv Rev. (2013) 65:1852-65. doi: 10.1016/j.addr.2013. 09.018

5. Wu Q, Yang Z, Nie Y, Shi Y, Fan D. Multi-drug resistance in cancer chemotherapeutics: mechanisms and lab approaches. Cancer Lett. (2014) 347:159-66. doi: 10.1016/j.canlet.2014.03.013

6. Hu CM, Zhang L. Nanoparticle-based combination therapy toward overcoming drug resistance in cancer. Biochem Pharmacol. (2012) 83:110411. doi: 10.1016/j.bcp.2012.01.008

7. Saad M, Garbuzenko OB, Ber E, Chandna P, Khandare JJ, Pozharov VP, et al. Receptor targeted polymers, dendrimers, liposomes: which nanocarrier is the most efficient for tumor-specific treatment and imaging? J Control Release. (2008) 130:107-14. doi: 10.1016/j.jconrel.2008.05.024

8. Vega-Villa KR, Takemoto JK, Yáñez JA, Remsberg CM, Forrest ML, Davies NM. Clinical toxicities of nanocarrier systems. Adv Drug Deliv Rev. (2008) 60:929-38. doi: 10.1016/j.addr.2007.11.007

9. Murakami M, Cabral H, Matsumoto Y, Wu S, Kano MR, Yamori T, et al. Improving drug potency and efficacy by nanocarrier-mediated subcellular targeting. Sci Transl Med. (2011) 3:64ra2. doi: 10.1126/scitranslmed.3001385

10. Patel TR. Nanocarrier-based therapies for CNS tumors. CNS Oncol. (2014) 3:115-22. doi: $10.2217 / \mathrm{cns} .14 .2$ for tumor treatment and drug resistance. These improvements are more conducive to nanocarriers for releasing drugs at the correct place, time, and dose, and thereby improve efficiency and reduce toxic side effects. Only the cross-connection between different fields can make nanomedicine play a great role in improving efficacy, safety, and overcoming drug resistance, it will also be personalized according to the characteristics of the patient's disease to achieve precise treatment.

\section{AUTHOR CONTRIBUTIONS}

JL and JianW design and wrote the whole manuscript. QX, RM, YL, and JY carried out various literature survey studies. MR, HL, and JiajW participated in the drawing of the figures. DL and ZX checked the format initially. All authors contributed to the article and approved the submitted version.

\section{FUNDING}

This work was supported by the National Natural Science Foundation of China (Grant Nos. 81873023 and 81473371), the Innovation Team in Chengdu University of Traditional Chinese Medicine (Grant No. CXTD2018004), and the Open Research Fund of the Key Laboratory of Southwestern Characteristic Chinese Medicine Resources, Chengdu University of Traditional Chinese Medicine (Grant No. 2020XSGG025).
11. Matsumura Y, Maeda H. A new concept for macromolecular therapeutics in cancer chemotherapy: mechanism of tumoritropic accumulation of proteins and the antitumor agent smancs. Cancer Res. (1986) 46:6387-92.

12. Karlsson J, Vaughan HJ, Green JJ. Biodegradable polymeric nanoparticles for therapeutic cancer treatments. Annu Rev Chem Biomol Eng. (2018) 9:105-27. doi: 10.1146/annurev-chembioeng-060817-084055

13. Gong W, Hu Z, Liang Y, Wang Y, Zheng R, Tan J, et al. Graphenebased multifunctional nanomaterials in cancer detection and therapeutics. J Nanosci Nanotechnol. (2018) 18:5155-70. doi: 10.1166/jnn.2018.14637

14. Lv M, Liu Y, Geng J, Kou X, Xin Z, Yang D. Engineering nanomaterials-based biosensors for food safety detection. Biosens Bioelectron. (2018) 106:1228. doi: 10.1016/j.bios.2018.01.049

15. Barenholz YC, Peer D. Liposomes, lipid biophysics, and sphingolipid research: from basic to translation research. Chem Phys Lipids. (2012) 165:363-4. doi: 10.1016/j.chemphyslip.2012.03.003

16. Keam B, Lee KW, Lee SH, Kim JS, Kim JH, Wu HG, et al. A phase II study of genexol-PM and cisplatin as induction chemotherapy in locally advanced head and neck squamous cell Carcinoma. Oncologist. (2019) 24:751-e231. doi: 10.1634/theoncologist.2019-0070

17. Silverman JA, Deitcher SR. Marqibo ${ }^{\circledR}$ (vincristine sulfate liposome injection) improves the pharmacokinetics and pharmacodynamics of vincristine. Cancer Chemother Pharmacol. (2013) 71:55564. doi: 10.1007/s00280-012-2042-4

18. Pietroiusti A, Campagnolo L, Fadeel B. Interactions of engineered nanoparticles with organs protected by internal biological barriers. Small. (2013) 9:1557-72. doi: 10.1002/smll.201201463

19. Meng H, Leong W, Leong KW, Chen C, Zhao Y. Walking the line: the fate of nanomaterials at biological barriers. Biomaterials. (2018) 174:4153. doi: 10.1016/j.biomaterials.2018.04.056

20. Meng $\mathrm{H}$, Zhao $\mathrm{Y}$, Dong J, Xue M, Lin YS, Ji Z, et al. Two-wave nanotherapy to target the stroma and optimize gemcitabine delivery to a human pancreatic cancer model in mice. ACS Nano. (2013) 7:1004865. doi: $10.1021 / \mathrm{nn} 404083 \mathrm{~m}$ 
21. Wilhelm S, Tavares AJ, Dai Q, Ohta S, Audet J, Dvorak H, et al. Analysis of nanoparticle delivery to tumours. Nat Rev Mater. (2016) 1:16014. doi: 10.1038/natrevmats.2016.14

22. Yu B, Ruan M, Dong X, Yu Y, Cheng H. The mechanism of the opening of the blood-brain barrier by borneol: a pharmacodynamics and pharmacokinetics combination study. J Ethnopharmacol. (2013) 150:1096108. doi: 10.1016/j.jep.2013.10.028

23. Zheng Q, Chen $\mathrm{ZX}$, Xu MB, Zhou XL, Huang YY, Zheng GQ, et al. Borneol, a messenger agent, improves central nervous system drug delivery through enhancing blood-brain barrier permeability: a preclinical systematic review and meta-analysis. Drug Deliv. (2018) 25:161733. doi: 10.1080/10717544.2018.1486471

24. Kou ZS. Extension of the Materia Medica. Beijing: China Medical Science Press 2012:91.

25. Li Y, Ren M, Wang J, Ma R, Chen H, Xie Q, et al. Progress in borneol intervention for ischemic stroke: a systematic review. Front Pharmacol. (2021) 12:606682. doi: 10.3389/fphar.2021.606682

26. Fan X, Chai L, Zhang H, Wang Y, Zhang B, Gao X. Borneol depresses P-glycoprotein function by a NF- $\mathrm{KB}$ signaling mediated mechanism in a blood brain barrier in vitro model. Int J Mol Sci. (2015) 16:2757688. doi: 10.3390/ijms161126051

27. Durand-Cavagna G, Duprat P, Molon-Noblot S, Delort P, Rozier A. Corneal endothelial changes with azone, a penetration enhancer. Lens Eye Toxic Res. (1989) 6:109-17.

28. Furrer P, Mayer JM, Plazonnet B, Gurny R. Ocular tolerance of absorption enhancers in ophthalmic preparations. AAPS Pharm Sci. (2002) 4:E2. doi: 10.1208/ps040102

29. Duangjit S, Pamornpathomkul B, Opanasopit P, Rojanarata T, Obata Y, Takayama K, et al. Role of the charge, carbon chain length, and content of surfactant on the skin penetration of meloxicam-loaded liposomes. Int J Nanomedicine. (2014) 9:2005-17. doi: 10.2147/IJN.S6 0674

30. Li Z, Sun D, Yang H, Liu X, Luan L, Bai J, et al. Effect of borneol on the distribution of danshensu to the eye in rabbit via oral administration. Curr Eye Res. (2010) 35:565-72. doi: 10.3109/0271368100371 8091

31. Xiong ZY, Xiao FM, Xu X, Wy XF, Jiang XM. Studies on pharmacological activity of borneol (Chinese). Zhongguo Zhong Yao Za Zhi. (2013) 38:786-90.

32. Wu CJ, Huang QW, Qi HY, Guo P, Hou SX. Promoting effect of borneol on the permeability of puerarin eye drops and timolol maleate eye drops through the cornea in vitro. Pharmazie. (2006) 61:783-8.

33. Yang H, Xun Y, Li Z, Hang T, Zhang X, Cui H. Influence of borneol on in vitro corneal permeability and on in vivo and in vitro corneal toxicity. J Int Med Res. (2009) 37:791-802. doi: 10.1177/1473230009037 00322

34. Jin D, Wang F, Qu L, Li Z, Jin L, Liu P, et al. The distribution and expression of claudin-5 and occludin at the rat blood-optic nerve barrier after borneol treatment. Mol Biol Rep. (2011) 38:913-20. doi: 10.1007/s11033-0100184-1

35. Liu J, Fu S, Wei N, Hou Y, Zhang X, Cui H. The effects of combined menthol and borneol on fluconazole permeation through the cornea ex vivo. Eur J Pharmacol. (2012) 688:1-5. doi: 10.1016/j.ejphar.2011. 12.007

36. Song J, Bi H, Xie X, Guo J, Wang X, Liu D. Natural borneol enhances geniposide ophthalmic absorption in rabbits. Int J Pharm. (2013) 445:16370. doi: 10.1016/j.ijpharm.2013.01.047

37. Cai Z, Hou S, Li Y, Zhao B, Yang Z, Xu S, et al. Effect of borneol on the distribution of gastrodin to the brain in mice via oral administration. J Drug Target. (2008) 16:178-84. doi: 10.1080/106118607017 94395

38. Huang L, Bai J, Yang H, Liu J, Cui H. Combined use of borneol or menthol with labrasol promotes penetration of baicalin through rabbit cornea in vitro. Pak J Pharm Sci. (2015) 28:1-7.

39. Cui Y, Li L, Zhang L, Li J, Gu J, Gong H, et al. Enhancement and mechanism of transdermal absorption of terpene-induced propranolol hydrochloride. Arch Pharm Res. (2011) 34:1477-85. doi: 10.1007/s12272-0110909-2
40. Lu Y, Du SY, Chen XL, Wu Q, Song X, Xu B, et al. Enhancing effect of natural borneol on the absorption of geniposide in rat via intranasal administration. J Zhejiang Univ Sci B. (2011) 12:143-8. doi: 10.1631/jzus.B10 00121

41. Shen Q, Li X, Li W, Zhao X. Enhanced intestinal absorption of daidzein by borneol/menthol eutectic mixture and microemulsion. AAPS Pharm Sci Tech. (2011) 12:1044-9. doi: 10.1208/s12249-011-9672-4

42. Ramsay L, Quillé ML, Orset C, de la Grange P, Rousselet E, Férec C, et al. Blood transcriptomic biomarker as a surrogate of ischemic brain gene expression. Ann Clin Transl Neurol. (2019) 6:1681-95. doi: 10.1002/acn3.50861

43. Abbott NJ, Patabendige AA, Dolman DE, Yusof SR, Begley DJ. Structure and function of the blood-brain barrier. Neurobiol Dis. (2010) 37:1325. doi: 10.1016/j.nbd.2009.07.030

44. Wu T, Zhang A, Lu H, Cheng Q. The role and mechanism of borneol to open the blood-brain barrier. Integr Cancer Ther. (2018) 17:80612. doi: $10.1177 / 1534735418767553$

45. Yin Y, Cao L, Ge H, Duanmu W, Tan L, Yuan J, et al. LBorneol induces transient opening of the blood-brain barrier and enhances the therapeutic effect of cisplatin. Neuroreport. (2017) 28:506-13. doi: 10.1097/WNR.0000000000000792

46. Li F, Feng J, Cheng Q, Zhu W, Jin Y. Delivery of 125I-cobrotoxin after intranasal administration to the brain: a microdialysis study in freely moving rats. Int J Pharm. (2007) 328:161-7. doi: 10.1016/j.ijpharm.2006.08.011

47. Yu B, Ruan M, Dong XP, Jin L, Qu HX. Effects of borneol at different intervals on the brain target effect of geniposide in rats. Chinese Pharmacol Bullet. (2012) 6:862-6.

48. Hou T, Li X, Peng C. Borneol enhances the antidepressant effects of asiaticoside by promoting its distribution into the brain. Neurosci Lett. (2017) 646:56-61. doi: 10.1016/j.neulet.2017.02.068

49. Chen ZZ, Lu Y, Du SY, Shang KX, Cai CB. Influence of borneol and muscone on geniposide transport through MDCK and MDCK-MDR1 cells as blood-brain barrier in vitro model. Int J Pharm. (2013) 456:739. doi: 10.1016/j.ijpharm.2013.08.017

50. Qi HP, Gao XC, Zhang LQ, Wei SQ, Bi S, Yang ZC, et al. In vitro evaluation of enhancing effect of borneol on transcorneal permeation of compounds with different hydrophilicities and molecular sizes. Eur J Pharmacol. (2013) 705:20-5. doi: 10.1016/j.ejphar.2013.02.031

51. Yi QF, Yan J, Tang SY, Huang H, Kang LY. Effect of borneol on the transdermal permeation of drugs with differing lipophilicity and molecular organization of stratum corneum lipids. Drug Dev Ind Pharm. (2016) 42:1086-93. doi: 10.3109/03639045.2015.1107095

52. Nie H. The Study on the Promoting Penetration Mechanism of Borneol and Menthol Involving the P-glycoprotein. (Dissertation/Master's thesis). Guangdong Pharmaceutical University, Guangzhou, China (2014).

53. Wang R, Wu Z, Yang S, Guo S, Dai X, Qiao Y, et al. A molecular interpretation on the different penetration enhancement effect of borneol and menthol towards 5-Fluorouracil. Int J Mol Sci. (2017) 18:2747. doi: 10.3390/ijms18122747

54. Wang S, Zang W, Zhao X, Feng W, Zhao M, He X, et al. Effects of borneol on pharmacokinetics and tissue distribution of notoginsenoside R1 and Ginsenosides Rg1 and Re in panax notoginseng in Rabbits. J Anal Methods Chem. (2013) 2013:706723. doi: 10.1155/2013/706723

55. Gao Y, Chen G, Luan X, Zou M, Piao H, Cheng G. Improved oral absorption of poorly soluble curcumin via the concomitant use of borneol. AAPS Pharm Sci Tech. (2019) 20:150. doi: 10.1208/s12249-019-1364-5

56. Chen Z, Gong X, Lu Y, Du S, Yang Z, Bai J, et al. Enhancing effect of borneol and muscone on geniposide transport across the human nasal epithelial cell monolayer. PLoS ONE. (2014) 9:e101414. doi: 10.1371/journal.pone.01 01414

57. Zhang L, Han L, Qin J, Lu W, Wang J. The use of borneol as an enhancer for targeting aprotinin-conjugated PEG-PLGA nanoparticles to the brain. Pharm Res. (2013) 30:2560-72. doi: 10.1007/s11095-013-1055-y

58. Tang S, Wang A, Yan X, Chu L, Yang X, Song Y, et al. Brain-targeted intranasal delivery of dopamine with borneol and lactoferrin co-modified nanoparticles for treating Parkinson's disease. Drug Deliv. (2019) 26:7007. doi: 10.1080/10717544.2019.1636420 
59. Song H, Wei M, Zhang N, Li H, Tan X, Zhang Y, et al. Enhanced permeability of blood-brain barrier and targeting function of brain via borneol-modified chemically solid lipid nanoparticle. Int J Nanomedicine. (2018) 13:186979. doi: 10.2147/IJN.S161237

60. Wang L, Zhao X, Du J, Liu M, Feng J, Hu K. Improved brain delivery of pueraria flavones via intranasal administration of borneol-modified solid lipid nanoparticles. Nanomedicine. (2019) 14:2105-19. doi: 10.2217/nnm-2018-0417

61. Wu HB, Wang SN, Shi L. Effects of borneol on the distribution of azidothymidine palmitate liposomes in mice. Chin Pharm J. (2009) 44:590.

62. Ren J, Zou M, Gao P, Wang Y, Cheng G. Tissue distribution of borneol-modified ganciclovir-loaded solid lipid nanoparticles in mice after intravenous administration. Eur J Pharm Biopharm. (2013) 83:1418. doi: 10.1016/j.ejpb.2012.10.018

63. Lv Z, Yang Y, Wang J, Chen J, Li J, Di L. Optimization of the preparation conditions of borneol-modified ginkgolide liposomes by response surface methodology and study of their blood brain barrier permeability. Molecules. (2018) 23:303. doi: 10.3390/molecules23020303

64. Ye $\mathrm{T}$, Wu Y, Shang $\mathrm{L}$, Deng $\mathrm{X}$, Wang $\mathrm{S}$. Improved lymphatic targeting: effect and mechanism of synthetic borneol on lymph node uptake of 7-ethyl-10-hydroxycamptothecin nanoliposomes following subcutaneous administration. Drug Deliv. (2018) 25:1461-71. doi: 10.1080/10717544.2018.1482973

65. Zhang Y, Zhang N, Song H, Li H, Wen J, Tan X, et al. Design, characterization and comparison of transdermal delivery of colchicine via borneol-chemically-modified and borneol-physically-modified ethosome. Drug Deliv. (2019) 26:70-7. doi: 10.1080/10717544.2018.1559258

66. Hu X, Cheng N, Zhao J, Piao X, Yan Y, Zhang Q, et al. Percutaneous absorption and brain distribution facilitation of borneol on tetramethylpyrazine in a microemulsion-based transdermal therapeutic system. Asian J Pharm Sci. (2019) 14:305-12. doi: 10.1016/j.ajps.2018. 06.003

67. Ru G, Han L, Qing J, Sheng J, Li R, Qiu M, et al. Effects of borneol on the pharmacokinetics of 9-nitrocamptothecin encapsulated in PLGA nanoparticles with different size via oral administration. Drug Deliv. (2016) 23:3417-23. doi: 10.1080/10717544.2016.1189466

68. Frikeche J, Maiti G, Chakravarti S. Small leucine-rich repeat proteoglycans in corneal inflammation and wound healing. Exp Eye Res. (2016) 151:1429. doi: 10.1016/j.exer.2016.08.015

69. Varela-Fernández R, Díaz-Tomé V, Luaces-Rodríguez A, Conde-Penedo A, García-Otero X, Luzardo-Álvarez A, et al. Drug delivery to the posterior segment of the eye: biopharmaceutic and pharmacokinetic considerations. Pharmaceutics. (2020) 12:269. doi: 10.3390/pharmaceutics12030269

70. Moiseev RV, Morrison P, Steele F, Khutoryanskiy VV. Penetration enhancers in ocular drug delivery. Pharmaceutics. (2019) 11:321. doi: 10.3390/pharmaceutics11070321

71. Gote V, Ansong M, Pal D. Prodrugs and nanomicelles to overcome ocular barriers for drug penetration. Expert Opin Drug Metab Toxicol. (2020) 16:885-806. doi: 10.1080/17425255.2020.1803278

72. Mahaling B, Katti DS. Understanding the influence of surface properties of nanoparticles and penetration enhancers for improving bioavailability in eye tissues in vivo. Int J Pharm. (2016) 501:1-9. doi: 10.1016/j.ijpharm.2016.01.053

73. Prausnitz MR, Langer R. Transdermal drug delivery. Nat Biotechnol. (2008) 26:1261-8. doi: 10.1038/nbt.1504

74. Kiselev MA. Conformation of ceramide 6 molecules and chainflip transitions in the lipid matrix of the outermost layer of mammalian skin, the stratum corneum. Crystallogr Rep. (2007) 52:525-8. doi: 10.1134/S1063774507030340

75. Marwah H, Garg T, Goyal AK, Rath G. Permeation enhancer strategies in transdermal drug delivery. Drug Deliv. (2016) 23:564-78. doi: 10.3109/10717544.2014.935532

76. Fox LT, Gerber M, Plessis JD, Hamman JH. Transdermal drug delivery enhancement by compounds of natural origin. Molecules. (2011) 16:1050740. doi: 10.3390/molecules 161210507

77. Yin Q, Shi X, Ding H, Dai X, Wan G, Qiao Y. Interactions of borneol with DPPC phospholipid membranes: a molecular dynamics simulation study. Int J Mol Sci. (2014) 15:20365-81. doi: 10.3390/ijms151120365
78. Dai X, Yin Q, Wan G, Wang R, Shi X, Qiao Y. Effects of concentrations on the transdermal permeation enhancing mechanisms of borneol: a coarse-grained molecular dynamics simulation on mixed-bilayer membranes. Int J Mol Sci. (2016) 17:1349. doi: 10.3390/ijms170 81349

79. Tomita M, Hayashi M, Awazu S. Absorption-enhancing mechanism of EDTA, caprate, and decanoylcarnitine in Caco-2 cells. J Pharm Sci. (1996) 85:608-11. doi: 10.1021/js9504604

80. Shaikh J, Ankola DD, Beniwal V, Singh D, Kumar MN. Nanoparticle encapsulation improves oral bioavailability of curcumin by at least 9-fold when compared to curcumin administered with piperine as absorption enhancer. Eur J Pharm Sci. (2009) 37:223-30. doi: 10.1016/j.ejps.2009. 02.019

81. Crowe TP, Greenlee M, Kanthasamy AG, Hsu WH. Mechanism of intranasal drug delivery directly to the brain. Life Sci. (2018) 195:4452. doi: 10.1016/j.lfs.2017.12.025

82. Friberg S, Nyström AM. Nanomedicine: will it offer possibilities to overcome multiple drug resistance in cancer? J Nanobiotechnology. (2016) 14:17. doi: 10.1186/s12951-016-0172-2

83. Goos J, Cho A, Carter LM, Dilling TR, Davydova M, Mandleywala $\mathrm{K}$, et al. Delivery of polymeric nanostars for molecular imaging and endoradiotherapy through the enhanced permeability and retention (EPR) effect. Theranostics. (2020) 10:567-84. doi: 10.7150/thno. 36777

84. Chen H, Zhao Y, Wang H, Nie G, Nan K. Co-delivery strategies based on multifunctional nanocarriers for cancer therapy. Curr Drug Metab. (2012) 13:1087-96. doi: 10.2174/1389200128028 49995

85. Kemp JA, Shim MS, Heo CY, Kwon YJ. “Combo" nanomedicine: codelivery of multi-modal therapeutics for efficient, targeted, and safe cancer therapy. Adv Drug Deliv Rev. (2016) 98:3-18. doi: 10.1016/j.addr.2015. 10.019

86. Shen S, Liu M, Li T, Lin S, Mo R. Recent progress in nanomedicinebased combination cancer therapy using a site-specific co-delivery strategy. Biomater Sci. (2017) 5:1367-81. doi: 10.1039/C7BM0 0297A

87. Yang $\mathrm{X}$, Yi C, Luo N, Gong C. Nanomedicine to overcome cancer multidrug resistance. Curr Drug Metab15. (2014) 632-49. doi: 10.2174/1389200215666140926154443

88. Kydd J, Jadia R, Velpurisiva P, Gad A, Paliwal S, Rai P. Targeting strategies for the combination treatment of cancer using drug delivery systems. Pharmaceutics. (2017) 9:46. doi: 10.3390/pharmaceutics9040046

89. Abouzeid AH, Patel NR, Torchilin VP. Polyethylene glycolphosphatidylethanolamine (PEG-PE)/vitamin E micelles for co-delivery of paclitaxel and curcumin to overcome multi-drug resistance in ovarian cancer. Int J Pharm. (2014) 464:178-84. doi: 10.1016/j.ijpharm.2014. 01.009

90. Zeng Y, Yang Z, Li H, Hao Y, Liu C, Zhu L, et al. Multifunctional nanographene oxide for targeted gene-mediated thermochemotherapy of drug-resistant tumour. Sci Rep. (2017) 7:43506. doi: 10.1038/srep 43506

91. Wang $\mathrm{H}$, Agarwal $\mathrm{P}$, Zhao $\mathrm{S}$, $\mathrm{Xu} \mathrm{RX}, \mathrm{Yu} J, \mathrm{Lu} \mathrm{X}$, et al. Hyaluronic acid-decorated dual responsive nanoparticles of pluronic F127, PLGA, and chitosan for targeted co-delivery of doxorubicin and irinotecan to eliminate cancer stem-like cells. Biomaterials. (2015) 72:74-89. doi: 10.1016/j.biomaterials.2015. 08.048

92. Liu B, Han L, Liu J, Han S, Chen Z, Jiang L. Co-delivery of paclitaxel and TOS-cisplatin via TAT-targeted solid lipid nanoparticles with synergistic antitumor activity against cervical cancer. Int J Nanomedicine. (2017) 12:955-68. doi: 10.2147/IJN.S115136

93. Shao Z, Shao J, Tan B, Guan S, Liu Z, Zhao Z, et al. Targeted lung cancer therapy: preparation and optimization of transferrin-decorated nanostructured lipid carriers as novel nanomedicine for co-delivery of anticancer drugs and DNA. Int J Nanomedicine. (2015) 10:122333. doi: 10.2147/IJN.S77837

94. Lv L, Liu C, Chen C, Yu X, Chen G, Shi Y, et al. Quercetin and doxorubicin co-encapsulated biotin receptor-targeting nanoparticles for 
minimizing drug resistance in breast cancer. Oncotarget. (2016) 7:3218499. doi: 10.18632/oncotarget.8607

95. Song CK, Balakrishnan P, Shim CK, Chung SJ, Kim DD. Enhanced in vitro cellular uptake of P-gp substrate by poloxamer-modified liposomes (PMLs) in MDR cancer cells. J Microencapsul. (2011) 28:575-81. doi: 10.3109/02652048.2011.599436

96. Dong H, Tian L, Gao M, Xu H, Zhang C, Lv L, et al. Promising galactose-decorated biodegradable poloxamer 188-PLGA deblock copolymer nanoparticles of resibufogenin for enhancing liver cancer therapy. Drug Deliv. (2017) 24:1302-16. doi: 10.1080/10717544.2017.13 73165

97. Assanhou AG, Li W, Zhang L, Xue L, Kong L, Sun H, et al. Reversal of multidrug resistance by co-delivery of paclitaxel and lonidamine using a TPGS and hyaluronic acid dualfunctionalized liposome for cancer treatment. Biomaterials. (2015) 73:284-95. doi: 10.1016/j.biomaterials.2015.09.022

98. Lv L, Li X, Qian W, Li S, Jiang Y, Xiong Y, et al. Enhanced antiglioma efficacy by borneol combined with CGKRK-modified paclitaxel self-assembled redox-sensitive nanoparticles. Front Pharmacol. (2020) 11:558. doi: 10.3389/fphar.2020.00558

99. Zeng L, Chen J, Ji S, Chan L, Zheng W, Chen T. Construction of a cancer-targeted nanosystem as a payload of iron complexes to reverse cancer multidrug resistance. J Mater Chem B. (2015) 3:434554. doi: 10.1039/C4TB02010C

100. Zou L, Fu J, Li W, Yu T, Guo XH, Yang L. Preparation and characterization of ginsenoside- $\mathrm{Rh}_{2}$ lipid nanoparticles and synergistic effect with borneol in resisting tumor activity. China J Chinese Materia Medica. (2016) 41:1235-40.

101. Chen T, Yuan R. Natural Right-Handed Borneol Nanoparticles and Preparation Method and Application. Guangdong: CN109394690A (2019).

102. Chen T, Chen L. Polymer Loaded Natural D-Borneol Nanoparticles and Preparation Method and Application Thereof. Guangdong: CN109364022B (2020).

103. Lv C, Zhang R, Zou J, Li Y, Wang G, Li F. Preparation of borneol and brucea Javanica oil nanoemulsion and tumor suppression effect on glioma in Rats (Chinese). Chinese J Modern Appl Pharmacy. (2014) 31:780-6.

104. Ying FL. Preparation of Borneol and Brucea Javanica Oil Nanoemulsion and Study on Its Inhibitory Effects on Proliferation of Brain Glioma in Rats. (Dissertation/Master's thesis). Zhejiang Chinese Medical University, Hangzhou, China (2013).

105. Yuan R, Huang Y, Chan L, He D, Chen T. Engineering EHD1-targeted natural borneol nanoemulsion potentiates therapeutic efficacy of gefitinib against non-small lung cancer. ACS Appl Mater Interfaces. (2020) 12:4571427. doi: 10.1021 /acsami.0c08069

106. Wu Y, Wang S, Shang L, Zhang H, Qin J, Ren Y, et al. Effect of borneol as a penetration enhancer on brain targeting of nanoliposomes: facilitate direct delivery to neurons. Nanomedicine. (2018) 13:270927. doi: 10.2217/nnm-2018-0282

107. Li JJ, Guo MM, Han SP, Sun Y, Fei WD, Xu XI, et al. Preparation and in vitro evaluation of borneol and folic acid co-modified doxorubicin loaded PAMAM drug delivery system. Acta Pharmaceutica Sinica. (2015) 50:899905.

108. Xu X, Li J, Han S, Tao C, Fang L, Sun Y, et al. A novel doxorubicin loaded folic acid conjugated PAMAM modified with borneol, a nature dual-functional product of reducing PAMAM toxicity and boosting BBB penetration. Eur J Pharm Sci. (2016) 88:178-90. doi: 10.1016/j.ejps.2016.02.015

109. Han S, Zheng $\mathrm{H}$, Lu Y, Sun $\mathrm{Y}$, Huang A, Fei W, et al. A novel synergetic targeting strategy for glioma therapy employing borneol combination with angiopep-2-modified, DOX-loaded PAMAM dendrimer. J Drug Target. (2018) 26:86-94. doi: 10.1080/1061186X.2017.13 44849

110. Zou L, Wang D, Hu Y, Fu C, Li W, Dai L, et al. Drug resistance reversal in ovarian cancer cells of paclitaxel and borneol combination therapy mediated by PEG-PAMAM nanoparticles. Oncotarget. (2017) 8:6045368. doi: 10.18632/oncotarget. 19728

111. Yao Q, Gutierrez DC, Hoang NH, Kim D, Wang R, Hobbs C, et al. Efficient codelivery of paclitaxel and curcumin by novel bottlebrush copolymer-based micelles. Mol Pharm. (2017) 14:2378-89. doi: 10.1021/acs.molpharmaceut.7b00278
112. Ding J, Sun Y, Li J, Wang H, Mao S. Enhanced blood-brain barrier transport of vinpocetine by oral delivery of mixed micelles in combination with a message guider. J Drug Target. (2017) 25:532-40. doi: 10.1080/1061186X.2017.1289541

113. Meng L, Chu X, Xing H, Liu X, Xin X, Chen L, et al. Improving glioblastoma therapeutic outcomes via doxorubicin-loaded nanomicelles modified with borneol. Int J Pharm. (2019) 567:118485. doi: 10.1016/j.ijpharm.2019.1 18485

114. Guo X, Wu G, Wang H, Chen L. Pep-1\&borneol-bifunctionalized carmustine-loaded micelles enhance anti-glioma efficacy through tumor-targeting and BBB-penetrating. J Pharm Sci. (2019) 108:1726-35. doi: 10.1016/j.xphs.2018.11.046

115. Tang B, Fang GH, Gao Y, Liu Y, Liu JW, Zou MJ, et al. Coencapsulation of borneol and paclitaxel by liprosomes improved antitumor effect in a xenografted glioma model. RSC Adv. (2015) 5:10661320. doi: 10.1039/C5RA22233H

116. Tang B, Fang GH, Gao Y, Liu Y, Liu JW, Zou MJ, et al. Lipid-albumin nanoassemblies co-loaded with borneol and paclitaxel for intracellular drug delivery to C6 glioma cells with P-gp inhibition and its tumor targeting. Asian J Pharm Sci. (2015) 57:4. doi: 10.1016/j.ajps.2015. 04.004

117. Zhang S, Asghar S, Yang L, Hu Z, Chen Z, Shao F, et al. Borneol and poly (ethylene glycol) dual modified BSA nanoparticles as an itraconazole vehicle for brain targeting. Int J Pharm. (2020) 575:119002. doi: 10.1016/j.ijpharm.2019.119002

118. Liu S, Long $\mathrm{Y}$, $\mathrm{Yu}$ S, Zhang $\mathrm{D}$, Yang $\mathrm{Q}, \mathrm{Ci}$ Z, et al. Borneol in cardio-cerebrovascular diseases: pharmacological actions, mechanisms, and therapeutics. Pharmacol Res. (2021) 169:105627. doi: 10.1016/j.phrs.2021.105627

119. Cao WQ, Li Y, Hou YJ, Yang MX, Fu XQ, Zhao BS, et al. Enhanced anticancer efficiency of doxorubicin against human glioma by natural borneol through triggering ROS-mediated signal. Biomed Pharmacother. (2019) 118:109261. doi: 10.1016/j.biopha.2019.109261

120. Chen J, Li L, Su J, Li B, Zhang X, Chen T. Proteomic analysis of G2/M arrest triggered by natural borneol/curcumin in HepG2 cells, the importance of the reactive oxygen species-p53 pathway. J Agric Food Chem. (2015) 63:6440-9. doi: 10.1021/acs.jafc.5b01773

121. Cao WQ, Zhai XQ, Ma JW, Fu XQ, Zhao BS, Zhang P, et al. Natural borneol sensitizes human glioma cells to cisplatin-induced apoptosis by triggering ROS-mediated oxidative damage and regulation of MAPKs and PI3K/AKT pathway. Pharm Biol. (2020) 58:72-9. doi: 10.1080/13880209.2019.17 03756

122. Chen J, Ding J, Wang Y, Cheng J, Ji S, Zhuang X, et al. Sequentially responsive shell-stacked nanoparticles for deep penetration into solid tumors. $A d v$ Mater. (2017) 29:201701170. doi: 10.1002/adma.201701170

123. Zhu S, Qian L, Hong M, Zhang L, Pei Y, Jiang Y. RGD-modified PEGPAMAM-DOX conjugate: in vitro and in vivo targeting to both tumor neovascular endothelial cells and tumor cells. Adv Mater. (2011) 23:H849. doi: 10.1002/adma.201003944

124. Zhu S, Hong M, Tang G, Qian L, Lin J, Jiang Y, et al. Partly PEGylated polyamidoamine dendrimer for tumor-selective targeting of doxorubicin: the effects of PEGylation degree and drug conjugation style. Biomaterials. (2010) 31:1360-71. doi: 10.1016/j.biomaterials.2009.10.044

125. Khot VM, Salunkhe AB, Pricl S, Bauer J, Thorat ND, Townley H. Nanomedicine-driven molecular targeting, drug delivery, and therapeutic approaches to cancer chemoresistance. Drug Discov Today. (2021) 26:72439. doi: 10.1016/j.drudis.2020.12.016

126. Chavanpatil MD, Patil Y, Panyam J. Susceptibility of nanoparticleencapsulated paclitaxel to P-glycoprotein-mediated drug efflux. Int J Pharm. (2006) 320:150-6. doi: 10.1016/j.ijpharm.2006.03.045

127. Szakács G, Paterson JK, Ludwig JA, Booth-Genthe C, Gottesman MM. Targeting multidrug resistance in cancer. Nat Rev Drug Discov. (2006) 5:219-34. doi: 10.1038/nrd1984

128. He H, Shen Q, Li J. Effects of borneol on the intestinal transport and absorption of two P-glycoprotein substrates in rats. Arch Pharm Res. (2011) 34:1161-70. doi: 10.1007/s12272-011-0714-y

129. Hernández-Pedro NY, Rangel-López E, Magaña-Maldonado R, de la Cruz VP, del Angel AS, Pineda B, et al. Application of nanoparticles 
on diagnosis and therapy in gliomas. Biomed Res Int. (2013) 2013:351031. doi: 10.1155/2013/351031

130. Xue J, Zhao Z, Zhang L, Xue L, Shen S, Wen Y, et al. Neutrophil-mediated anticancer drug delivery for suppression of postoperative malignant glioma recurrence. Nat Nanotechnol. (2017) 12:692-700. doi: 10.1038/nnano.2017.54

131. Ragelle H, Danhier F, Préat V, Langer R, Anderson DG. Nanoparticlebased drug delivery systems: a commercial and regulatory outlook as the field matures. Expert Opin Drug Deliv. (2017) 14:851-64. doi: 10.1080/17425247.2016.1244187

Conflict of Interest: The authors declare that the research was conducted in the absence of any commercial or financial relationships that could be construed as a potential conflict of interest.
Publisher's Note: All claims expressed in this article are solely those of the authors and do not necessarily represent those of their affiliated organizations, or those of the publisher, the editors and the reviewers. Any product that may be evaluated in this article, or claim that may be made by its manufacturer, is not guaranteed or endorsed by the publisher.

Copyright (C) $2021 \mathrm{Li}$, Xie, Ma, Li, Yuan, Ren, Li, Wang, Lu, Xu and Wang. This is an open-access article distributed under the terms of the Creative Commons Attribution License (CC BY). The use, distribution or reproduction in other forums is permitted, provided the original author(s) and the copyright owner(s) are credited and that the original publication in this journal is cited, in accordance with accepted academic practice. No use, distribution or reproduction is permitted which does not comply with these terms. 